\title{
IV.2 Die Gründung der Europäischen Wirtschafts- und Atomgemeinschaft 1955-1958
}

\section{IV.2.1 „Relance européenne“ 1955}

\section{"Der Gedanke an ein integriertes Europa ist stark und lebendig“}

Das Scheitern der Europäischen Verteidigungsgemeinschaft im August 1954 hatte die Vision eines politisch geeinten Europa in weite Ferne gerückt. Aus der Sicht der Bundesrepublik endete damit der zweite Abschnitt deutscher Nachkriegspolitik, der durch die Orientierung auf die europäisch-atlantische Gemeinschaft mit dem Ziel einer europäischen politischen Föderation gekennzeichnet war ${ }^{1}$. Die mit dem Inkrafttreten der Pariser Verträge im Mai 1955 beginnende dritte Periode wurde mitunter als „Dulles-Phase“ tituliert, weil sich die Bundesrepublik angeblich nunmehr vor allem an die amerikanische Hegemonialmacht angelehnt habe ${ }^{2}$. In dieser prägnanten Einseitigkeit trifft dies gewiß nicht zu, zeichneten sich die folgenden Jahre doch auch durch eine beispiellose Zusammenarbeit mit dem französischen Nachbarn aus. Man könnte sie also mit einiger Berechtigung durchaus auch als „Pinay/Mollet-Phase" bezeichnen, geprägt von dem Bemühen der Regierungen in Bonn und Paris, den europapolitischen Schaden zu beheben.

Beiderseits des Rheins war das Streben nach der europäischen Einigung ungeachtet des „dies ater" im August 1954 nie völlig erlahmt ${ }^{3}$. Schon am Tage nach dem Scheitern der EVG in der Assemblée Nationale definierte Bundeskanzler Adenauer als erste Richtlinie der deutschen Politik die „Fortsetzung der Politik der europäischen politischen Integration " ${ }^{4}$. Gewiß handelte es sich dabei zunächst um eine „Absichtserklärung"5, die bis zum Frühjahr 1955 hinter die prioritären Ziele Souveränität und NATO-Beitritt zurückzutreten hatte. Dennoch wird man Adenauers Europapolitik nicht als bloße Rhetorik abtun können. Die außen--, sicherheits- und außenwirtschaftspolitischen Gegebenheiten in der Bundesrepublik ließen dies auch gar nicht zu. Schon aus „Gründen der Selbsterhaltung" sah der Kanzler „die unabwendbare Pflicht, dafür zu sorgen, daß dieses Europa wieder ein selbständiger und einflußreicher Faktor in der Weltpolitik wird"6.

Während die Christdemokraten die europäische Integration auf keinen Fall aus dem Kanon deutscher Interessen streichen wollten, setzte sich bei den Freidemokraten allmählich eine „europapolitische Neuorientierung“ durch, die im Sinne ihres Parteivorsitzenden Dehler mehr und mehr den Nationalstaat als Basis der Europapolitik betrachtete ${ }^{7}$. Demgegenüber gewann die SPD-Opposition nach der

I Vgl. Besson, Außenpolitik, S. 100.

2 Schwarz, Konzept, S. 86; s.a. Besson, Außenpolitik, S. 153-170 u. 185.

3 Zum Neubeginn der Bemühungen um die europäische Integration nach 1954 grundlegend: Küsters, Gründung; Serra (Hg.), Rilancio; Weilemann, Anfänge; s.a. den Überblick in: Gerbet, Construction, S. 163-195.

4 BA, NL Blankenhorn, Bd. 32a, Bl. 30, Tb. 31. 8. 1954; s.a. Kap. III.4.4.

5 Köhler, Adenauer, S. 836.

6 Erklärung Adenauers in der Sitzung des CDU-Bundesvorstandes, 5. 2. 1955, in: Buchstab (Bearb.), Protokolle 1953-1957, S. 371.

7 Jeutter, EWG, S. 126; s.a. Klingl, „Das ganze Deutschland“, S. 157-159. 
Trennung des Faktors Verteidigung von der Europapolitik ein positives Verhältnis zur europäischen Einigung. Der Fehlschlag des eigenen europapolitischen Ansatzes zeichnete dafür ebenso verantwortlich wie innerparteiliche Einflußverschiebungen, die proeuropäische Haltung der Gewerkschaften, die (vermeintliche) Bereinigung des Saarproblems oder die Erfahrung sozialdemokratischer Parlamentarier in den europäischen Institutionen ${ }^{8}$. Freilich beließen es Opposition und Koalition im Bewußtsein der europapolitischen Baisse zunächst bei Willensbekundungen ohne konkrete neue Initiativen. Mitunter gehegte Hoffnungen, NATO und WEU könnten die europapolitische Stagnation aufbrechen, erwiesen sich rasch als verfehlt. Die Atlantische Gemeinschaft war und blieb ein Allianzsystem, und auch die Westeuropäische Union enthielt „kein wirklich vorwärtstreibendes Element der Integration", wobei die Beteiligung Großbritanniens für die Zukunft kaum Besserung erwarten ließ9.

Wenngleich man sich hauptsächlich auf die Behebung der nationalen Wirtschaftsmisere konzentrierte, stand auch Frankreich einer politischen und wirtschaftlichen Integration nicht gänzlich ablehnend gegenüber. Traumatisiert durch den Fehlschlag der EVG dachte man aber bei der Weiterführung der europäischen Zusammenarbeit vor allem an die Errichtung des Rüstungspools und die Lösung der Saarfrage ${ }^{10}$, während die supranationale Kooperation den meisten Politikern vorerst diskreditiert schien.

Allein die BENELUX-Staaten mochten sich mit dem Stillstand der europäischen Einigung nicht einfach abfinden. Aufgrund der jahrelangen Diskussionen über die Europäische Politische Gemeinschaft waren ihre Experten zu dem Urteil gekommen, daß eine politische Vereinigung nicht ohne wirtschaftliches Fundament existieren könne. Ausgehend vom Beyen-Plan, erarbeiteten sie im Sommer 1954 ein Konzept zur Schaffung eines Gemeinsamen Marktes ${ }^{11}$. Während in London und Paris die Verträge über die Neuregelung des westeuropäisch-atlantischen Beziehungsgeflechtes ausgehandelt wurden, traf sich der belgische Außenminister Spaak mit dem Präsidenten der Hohen Behörde, Monnet, um über Möglichkeiten zur Ausdehnung der Kompetenzen der EGKS auf weitere Sektoren zu diskutieren. Monnet hatte bereits unmittelbar nach der Pleite der EVG den Entschluß gefaßt, sein Amt aufzugeben, um völlig freie Hand für eine neue Initiative zu haben ${ }^{12}$. Jetzt kam er mit Spaak überein, die Debatte zunächst im Kreis der eigenen Mitarbeiter zu vertiefen und dann den nationalen Regierungen entsprechende Vorschläge zu unterbreiten ${ }^{13}$. Ermuntert wurde er dazu nicht zuletzt auch von Adenauer, der ihm am 25. 10. nach seinen Unterredungen mit Mendès France versicherte, man sei sich während der Pariser Konferenz einig gewesen, „daß der Gedanke an ein integriertes Europa stark und lebendig" sei. Der Fehlschlag der EVG dürfe nicht dahin mißverstanden werden, „als wenn man die Integration Europas nicht wolle“ ${ }^{14}$.

8 Vgl. Paterson, SPD, S. 115-122.

9 Aufzeichnung Hallstein, 30. 3. 1955, Streng vertraulich, in: BDFD I, S. 582-586, hier S. 583.

$10 \mathrm{Vgl.} \mathrm{Kap.} \mathrm{III.3.4} \mathrm{u.} \mathrm{III.4.4.}$

11 Vgl. Kap. Ill.2.2; Küsters, Gründung, S. 65.

12 S. Monnet, Erinnerungen, S. 506; Rieben, Guerres européennes, S. 138; Schröder, Jean Monnet, S. 378-385.

13 S. Spaak, Memoiren, S. 297 f.; Duchêne, Jean Monnet, S. 262 f.; Küsters, Gründung, S. 66 f.

14 Adenauer an Monnet, 25. 10. 1954, in: Adenauer, Briefe 1953-1955, S. 181. 
Einige Wochen später verständigten sich Monnet und Spaak während einer zweiten Besprechungsrunde darüber, am Organisationsaufbau der Montanunion festzuhalten, die vom Schuman-Plan initiierte sektorale Integration aber auszuweiten. Als mögliche neue Zuständigkeitsbereiche nahmen sie das Transportwesen und den Energiesektor ins Visier ${ }^{15}$. Wie er dem französischen Botschafter in Brüssel verdeutlichte, ging es dem belgischen Außenminister bei seiner Suche nach Möglichkeiten zur „relance de l'idée européenne“ aber nicht nur um eine Ausweitung der Kompetenzen der EGKS. Nach diversen Gesprächen mit seinen Kollegen aus Luxemburg und den Niederlanden dachte er inzwischen darüber hinaus an einen Neuanlauf zur wirtschaftlichen Integration, "comme but essentiel, le marché commun", sowie an die Schaffung einer europäischen Freihandelszone mit sukzessive geminderten Zöllen ${ }^{16}$. Unschwer herauszuhören war aus seiner Argumentation die von allen BENELUX-Staaten geteilte Sorge vor der Marginalisierung bzw. einer wirtschaftlichen Hegemonie der beiden großen Nachbarn, die nach den deutsch-französischen Wirtschaftsabsprachen von La Celle-St.-Cloud noch an Virulenz gewann ${ }^{17}$.

Am 30. 11. gab Monnet auf einer außerordentlichen Sitzung der Gemeinsamen Versammlung der EGKS den Verzicht auf eine Verlängerung seines Präsidentenamtes nach Ablauf des Mandats im Februar 1955 bekannt und verband dies mit einem lebhaften Plädoyer für einen Neuanlauf zur europäischen Integration ${ }^{18}$. Seine Rede zeigte umgehend Wirkung. Wenngleich die Abgeordneten keine einhellige Auffassung über konkrete Maßnahmen vertraten, sprachen sie sich in einer interfraktionellen Entschließung einvernehmlich für Fortschritte bei der Einigung Europas aus ${ }^{19}$. Mit diesem Votum im Rücken begab sich Monnet nun an die mit Spaak verabredete Arbeit. Zum Kreis seiner Berater gehörten wie schon in der Entwicklungsphase des Schuman-Plans im Frühjahr $1950^{20}$ Pierre Uri und Etienne Hirsch, außerdem Robert Marjolin, der Generalsekretär der OEEC, und Louis Armand, Generaldirektor der Staatlichen Französischen Eisenbahnen SNCF. Namentlich Armand führte ihm die Notwendigkeit einer engen Zusammenarbeit auf dem Energiesektor vor Augen und brachte ihm die Idee einer europäischen Atomorganisation nahe, für die er den Namen „EURATOM“ kreierte. Monnet ließ sich davon überzeugen, daß kein europäischer Staat allein dazu in der Lage sei, die enormen Investitionsmittel zum Aufbau einer Nuklearindustrie aufzubringen. In Anbetracht der zu erwartenden Schwierigkeiten bei der Koordinierung der Forschungszusammenarbeit schien es durchaus sinnvoll, neben der Hohen Behörde eine eigenständige Organisation für die friedliche Nutzung der Atomenergie aufzubauen, zumal sie die Chance bot, die

15 S. Monnet, Erinnerungen, S. 507; Küsters, Gründung, S. 72 f.; Schröder, Jean Monnet, S. 388 f.

16 Rivière an Mendès France, Tel. 717, 30. 11. 1954, in: DDF 1954, S. 822 f., hier S. 822.

17 S. ders. an dens., Tel. 707/12, 30.11. 1954, in: ebd., S. 820f.; Beyen, Spel, S. 237; Küsters, Gründung, S. $77 \mathrm{f}$.

18 S. Monnet, Erinnerungen, S. 506f. Die Regierungen hatte er bereits am 10.11. 1954 von dieser Absicht in Kenntnis gesetzt (Monnet an Adenauer, 10.11. 1954, in: Hollmann, Nachfolge, S. 187). Vgl. ausführlich ebd.

19 S. Entschließung der Gemeinsamen Versammlung der EGKS, 30.11. 1954, in: Bulletin 1954, S. 2114; Küsters, Gründung, S. 71.

20 Vgl. Kap. III.2.1. 
industriellen und finanziellen Ressourcen der Deutschen trotz ihres Verzichts auf die Produktion von ABC-Waffen einzubinden und die Briten für die europäische Integration zu gewinnen ${ }^{21}$. Geradezu euphorisch glaubte Monnet gar daran, die Atomenergie zum „véritable moteur de la relance européenne“ aufbauen zu können ${ }^{22}$. Nicht alle seine Mitarbeiter zeigten sich von diesen Überlegungen überzeugt. Namentlich Uri beurteilte eine Ausdehnung der Befugnisse der Hohen Behörde auf andere Wirtschaftsbereiche skeptisch, hielt auch die Schaffung eines Atompools für wenig realistisch, weil den EGKS-Staaten das Wissen und die Mittel fehlten ${ }^{23}$.

Vorbehalte meldete auch die Bundesregierung an. In mehreren Gesprächen mit Monnet und Uri äußerte der Leiter der Unterabteilung Zwischen- und überstaatliche Organisationen im Auswärtigen Amt, Ophüls, die Sorge, daß die Beteiligung der Bundesrepublik an einer Atomorganisation international auf Gegenwehr stoßen könnte. Außerdem sah er Widerstände von seiten des Bundeswirtschaftsministers vorher, der die regionale Integration aus volkswirtschaftlichen Gründen ablehnte. Ein deutsches Engagement, so lautete seine Botschaft, sei nur erwägenswert, wenn dem deutschen Interesse an einer engeren wirtschaftlichen Zusammenarbeit Rechnung getragen würde 24 .

Damit war der Gedanke geboren, die Schaffung der Atomorganisation mit dem Konzept einer allgemeinen Wirtschaftsintegration $\mathrm{zu}$ verbinden. Uri faßte die Überlegungen schließlich in einem Arbeitspapier zusammen, das von Monnet und seinen Mitarbeitern von Dezember 1954 bis Februar 1955 mehrfach überarbeitet wurde. Es bestand im wesentlichen aus zwei Teilen: Ausweitung der Kompetenzen der EGKS auf die Sektoren Transport und klassische Energien; Schaffung einer neuen Behörde für die friedliche Nutzung der Atomenergie ${ }^{25}$. Monnet selbst dachte zusätzlich noch an die Schaffung einer Europäischen Rüstungsbehörde ${ }^{26}$. Für die Lancierung des Vorschlags kamen eigentlich nur die BENELUX-Staaten in Frage, denn Frankreich war kaum für eine neue Initiative zu gewinnen und wäre wohl auch nicht bereit gewesen, eine deutsche Anregung zu unterstützen. Als Datum für die Präsentation der vorbereiteten Deklaration nahm Monnet den 10. 2. 1955 ins Visier, den Tag, an dem er seinen Abschied vom Amt des Präsidenten der Hohen Behörde zu nehmen gedachte ${ }^{27}$.

Nachdem der Sturz der Regierung Mendès France am 5.2. diesen Zeitplan durchkreuzt hatte, versuchte Monnet, die Chancen für die Verwirklichung seines Vorhabens in Gesprächen mit verschiedenen Politikern und Regierungschefs auszuloten ${ }^{28}$. Die Ergebnisse fielen nicht nur ermutigend aus. In Frankreich konnte zwar von einer "gesicherten potentiellen Majorität für intensivere Formen der europäischen Zusammenarbeit“ ausgegangen werden, da letztlich nur kleine Minderheiten der Radikalsozialisten, Sozialisten und Kommunisten dagegen einge-

21 S. Monnet, Erinnerungen, S. 507-509; Küsters, Gründung, S. 73-75.

22 Gerbet, Construction, S. 166; s.a. Guillen, La France et la négociation du traité d'Euratom, S. 393 f.

$23 \mathrm{Vgl.} \mathrm{Bjøl,} \mathrm{La} \mathrm{France,} \mathrm{S.} \mathrm{383;} \mathrm{Küsters,} \mathrm{Gründung,} \mathrm{S.} 75$.

$24 \mathrm{Vgl}$. Bjøl, La France, S. 382; Küsters, Gründung, S. $75 \mathrm{f}$.

25 S. Gerbet, „Relance“ européenne, S. 70.

$26 \mathrm{Vgl}$. Wilkens, Jean Monnet, S. 110.

27 S. Monnet, Erinnerungen, S. 509; Duchêne, Jean Monnet, S. 263-266; Küsters, Gründung, S. 76.

28 S. Monnet, Erinnerungen, S. 509; Duchêne, Jean Monnet, S. 266-268; Küsters, Gründung, S. $76 f$. 
stellt waren ${ }^{29}$. Doch auch unter den Befürwortern der europäischen Einigung herrschte keineswegs Einvernehmen über Grad und Intensität der Kooperation. Gewiß, Antoine Pinay, der neue Außenminister, oder Robert Schuman, der das Justizressort übernahm, sagten Monnet sofort ihre Unterstützung zu $^{30}$. Ihnen zur Seite saß aber eine Reihe gaullistischer Minister, die einer supranationalen Integration entschieden ablehnend gegenüberstand. Edgar Faure, der Président du Conseil, tat gut daran, Rücksicht auf sie zu nehmen, wollte er das Kabinett nicht gefährden. Auch Staatspräsident Coty, der die europäische Zusammenarbeit prinzipiell begrüßte, riet ihm zur Zurückhaltung, weil er die Wunden nach dem Fiasko der EVG noch nicht verheilt sah und Sorge um den Bestand der Regierung äußerte ${ }^{31}$.

Die innenpolitische und innerkoalitionäre Gemengelage veranlaßte Pinay dazu, ein eigenes Konzept auszuarbeiten, das er Ende Februar den ihm gut bekannten Bundesminister Strauß vertraulich vorlegte. Sein Plan eines „Conseil Confédéral Européen" ging davon aus, Europa auf empirischem Wege durch eine langsame, andauernde Arbeit zu einigen und sowohl die Föderalisten als auch die Anhänger der nationalen Souveränität dafür zu gewinnen. Pinay plante dazu die Einberufung einer Außenministerkonferenz der EGKS-Staaten, die in einer feierlichen Erklärung die Interessengemeinschaft betonen und die Abhaltung der Konferenz in regelmäßigen Abständen verkünden sollte, so daß sich ein Europäischer Staatenbundsrat - natürlich mit Sitz in Paris - bilden konnte. Der Rat, dem Pinay ausdrücklich eine staatenbündische Zuständigkeit zuwies und den er für südeuropäische Länder oder Großbritannien offenzuhalten beabsichtigte, besaß zwei Aufgaben: die Harmonisierung der Tätigkeiten von Exekutiven und Legislativen seiner Mitglieder sowie die Schaffung neuer internationaler Organisationen. Um Ratifikationsdebatten durch die nationalen Parlamente zu vermeiden, wünschte Pinay den Gründungsakt auf einen einfachen Beschluß der Regierungen zu beschränken $^{32}$.

Im Gegensatz zu diesen auf die politische Kooperation zielenden Planungen Frankreichs konzentrierten sich die Niederlande weiterhin auf Ansätze zur wirtschaftlichen Einigung und nahmen dazu im Winter 1954/55 den alten Vorschlag einer europäischen Zollunion wieder auf ${ }^{33}$. In der Bundesrepublik waren die konzeptionellen Arbeiten über die künftige Integrationspolitik von drei Denkrichtungen geprägt. Das Auswärtige Amt, d.h. Hallstein und Ophüls, zielten auf

29 PA, Abt. 2, Bd. 888, Bl. 268-286, Schwarz-Liebermann an Ophüls, Aufzeichnung, März 1955; zur Haltung der genannten Parteien zur „relance européenne“ vgl. Bjøl, La France, S. 161-167, 183186 u. 237-241; O’Neill, Radical Party, S. 79-100.

30 S. Alphand, L'étonnement d'être, S. 269, Tb. 29. 1. 1955; Poidevin, Robert Schuman, S. 384 u. 406; Rimbaud, Pinay, S. 303.

31 Vgl. de Baecque, René Coty, S. 216.

32 BA, NL Blankenhorn, Bd. 43, Bl. 96-103, Aufzeichnung, 28. 2. 1955, Vertraulich (Übersetzung). In seinen Erinnerungen bezeichnet Adenauer dieses Schriftstück als eine „Aufzeichnung des deutschen Auswärtigen Amtes“ (Adenauer, Erinnerungen 1955-1959, S. 23). Der Duktus des Dokuments und die Tatsache, daß es als Übersetzung figuriert, legen aber den Schluß nahe, daß es sich in Wirklichkeit um ein französisches Aktenstück zum Pinay-Plan, möglicherweise sogar um den Pinay-Plan selbst handelt. Zur Unterrichtung von Strauß s. PA, Abg.-Liste Ref. 204, Bd. 7, AA an von Maltzan, Entwurf einer Instruktion 302.210-02...., o.D.

33 S. Beyen, Spel, S. 234 u. 237; Harryvan/Kersten, Netherlands, S. 132-136. 
einen europäischen Bundesstaat mit möglichst kompetenten und funktionsfähigen Institutionen. Nach dem Ende der EVG hatte Ophüls zunächst am Projekt einer politischen Union festgehalten, im Laufe der Diskussionen mit Monnet und dessen Beratern allerdings die Aussichtslosigkeit dieses Unterfangens erkannt. In Anbetracht der politischen Sachzwänge brachte er den Teilintegrationsplänen Monnets zur Schaffung einer Atombehörde mehr Sympathie entgegen als den Plänen Beyens für die Wirtschaftsintegration, deren Durchsetzung ihm problematisch anmutete ${ }^{34}$. Pinays Staatenbund-Plan empfand er in der inhaltlichen Ausfüllung als "dürftig" und vor allem von dem Wunsch geprägt, bei den bevorstehenden Parlamentswahlen als Versöhner der europapolitischen Gegensätze auftreten und möglichst viele Gaullisten in die Reihen der Indépendants herüberziehen zu können. Allerdings sah er in dem Vorhaben durchaus ausbaufähige Elemente „in der Richtung der Politischen Gemeinschaft" wie den Grundsatz der permanenten politischen Konsultation. Auch die Erkenntnis, daß die europäische Entwicklung von der Sechsergemeinschaft ausgehen müsse, aber England nicht vergessen dürfe, fand er lobenswert ${ }^{35}$.

Anders als die Beamten im Auswärtigen Amt ging Bundeswirtschaftsminister Erhard von einem funktionalen Integrationskonzept aus. Sein Ziel war die von Protektionismus, Handelshemmnissen und Devisenzwangsbewirtschaftung befreite wirtschaftspolitische Kooperation des ganzen freien Europa in engem Kontakt mit den USA und die Wiederherstellung eines freien Welthandels ${ }^{36}$. Während die "Institutionalisten“ in der Koblenzer Straße die Integration mit Hilfe der Übertragung bestimmter Befehls- und Steuerungsaufgaben an gemeinsame Institutionen zu erreichen gedachten und darauf setzten, daß eine allmähliche Fusionierung der nationalen Wirtschaften schließlich in einen politischen Zusammenschluß mündete, glaubten die „Funktionalisten“ um Erhard, eine wirtschaftliche Integration könne sich nur in einem umfassenden Rahmen unter Einschluß der USA und Großbritanniens vollziehen. Die in mehreren Stufen gedachte Realisierung dieses ,long-term-projects's sah zunächst - gewissermaßen als Pivot - die Versöhnung zwischen der Bundesrepublik und Frankreich sowie eine verstärkte bilaterale wirtschaftliche Zusammenarbeit der Nachbarn vor. Deren Kooperation betrachtete er aber keineswegs als Selbstzweck. Die deutsch-französische Verständigung hatte vielmehr dem Ziel einer „höhere[n] Verpflichtung zur Schaffung eines gemeinsamen und freien Europas, gerade auch im ökonomischen Bereich“ zu dienen. Sie durfte weder ein Exklusivbündnis manifestieren noch als Versuch einer „ökonomischen Achsenbildung Paris-Bonn" gedeutet werden, mußte vielmehr als Katalysator für die Einleitung einer zweiten Stufe fungieren, nämlich die einer wirtschaftspolitischen Annäherung des ganzen freien Europa. Diese Annäherung verstand Erhard - wie er am 7.12. 1954 in einer Rede vor dem Klub „Les Echos" in Paris ausführte - im Sinne einer "funktionalen Integration“ der Volkswirtschaften, d.h. eines Systems, bei dem das Verhalten der nationalen Regierungen nicht dem Diktat einer supranationalen Behörde unterworfen, sondern durch

34 Vgl. Küsters, Gründung, S. $79 \mathrm{f}$.

35 PA, B 17, Bd. 141, Bl. 76-79, Aufzeichnung Ophüls, 12.3.1955.

36 Vgl. Laitenberger, Ludwig Erhard, S. 127 f.; Lappenküper, „Ich bin wirklich ein guter Europäer", S. 87. 
sein inneres Ordnungsgefüge gewissermaßen erzwungen, also „durch die Ordnung des Systems an sich" erreicht werde ${ }^{37}$.

Diese Gedanken präzisierend, betonte er im März 1955 in einer privaten, auch dem Kanzler und anderen Kabinettsmitgliedern zugeleiteten, ursprünglich für Jean Monnet gedachten Studie, nur die funktionale Integration europäischer Staaten könne den Erfordernissen der modernen Staatenwelt entsprechen. Das überkommene System zwischenstaatlicher Kooperation hielt er für unzureichend, weil es die notwendige Qualitätsveränderung der internationalen Beziehungen nicht hervorrufe; die institutionelle Integration sah er mit dem Makel behaftet, daß die einzelnen Nationalstaaten der Möglichkeit einer eigenen Wirtschaftspolitik beraubt würden, ohne daß die supranationalen Behörden dafür wirksamen Ersatz oder gar höhere Effektivität böten. Die Fortsetzung branchenmäßiger Integrationen, so lautete sein Generalvorwurf gegen das institutionalistische Modell, führe letztlich nicht zur Verflechtung, sondern zu einer „Atomisierung der binnen- und außenwirtschaftlichen Beziehungen der Volkswirtschaften". Es war für ihn ganz offensichtlich ein Unding, „über Formen der politischen Verständigung wirtschaftliche Zusammenfassungen“ erreichen zu wollen, „die wegen der Gegensätzlichkeiten der Grundlagen, Vorstellungen und Ziele nicht auf einen Nenner zu bringen sind." Offen warnte er davor zu glauben, als leite die wirtschaftliche gleichsam automatisch zur politischen Integration über. Zwar anerkannte Erhard den „Primat der Politik“, doch hatte er keineswegs die Absicht, sich den Diplomaten des Auswärtigen Amtes kampflos unterzuordnen. ,Jede Integration [...] setzt immer eine vorherige Übereinstimmung hinsichtlich der Prinzipien, Systeme und Ziele des Handelns und Verhaltens voraus. ${ }^{\text {"38 }}$

Erhards „europapolitische Konfession" 39 fand weder im eigenen Haus noch in der Bundesregierung ungeteilte Zustimmung. Hans von der Groeben, Ministerialdirigent im Wirtschaftsministerium, und seine engsten Mitarbeiter befürworteten die europäische Einigung aus der Überzeugung heraus, daß der Nationalstaat künftig die anstehenden Probleme nicht allein bewältigen könne. Nach dem Scheitern der EVG wollte er die Montanunion als Grundpfeiler erhalten, das System der funktionalen Integration insgesamt aber erweitern. Die Auseinandersetzungen innerhalb des Ministeriums kreisten nun um die Frage, ob die funktionale Integration im Sinne des globalen Freihandelskonzepts mit dem Ziel einer weltweiten Handelsliberalisierung oder im Sinne eines beschränkten Freihandelskonzepts mit Blickrichtung auf die Gesamtintegration im Gemeinsamen Markt angegangen und wie sie institutionell abgesichert werden sollte ${ }^{40}$.

Für den Kanzler, der sich Mitte Dezember 1954 vor dem Bundestag abermals für die Fortsetzung der Einigung Europas ausgesprochen hatte ${ }^{41}$, stand hingegen weniger der Zwist $\mathrm{zw}$ wischen institutioneller oder funktionaler, sondern zwischen

37 Rede Erhards vor dem Klub „Les Echos" in Paris, 7. 12. 1954, in: ders., Wirtschaftspolitik, S. 253259, hier S. 253, 254 u. 257; s.a. Erhard an Adenauer, 13. 11. 1954, in: BDFD II, S. 383 f.

38 Studie Erhards, März 1955, Privat, Vertraulich, in: ebd., S. 712-728, hier S. 723, 727 u. 728 ; vgl. Laitenberger, Ludwig Erhard, S. $131 \mathrm{f}$; Lappenküper, „Ich bin wirklich ein guter Europäer", S. $88 \mathrm{f}$.

39 Hentschel, Ludwig Erhard, S. 225.

40 S. von der Groeben, Deutschland, S. 269-273; Küsters, Gründung, S. 83-86.

41 S. Regierungserklärung Adenauers, 15. 12. 1954, in: BT, Sten. Ber., Bd. 23, S. 3120-3130. 
politischer und ökonomischer Integration im Mittelpunkt. Adenauer befürchtete, die für ihn prioritäre politische Einigung werde durch die Forcierung des wirtschaftlichen Zusammenschlusses eher behindert ${ }^{42}$. Auch Hallstein und Ophüls hielten grundsätzlich an der Notwendigkeit zur politischen Integration fest. Sie waren aber dazu bereit, den Umweg über die Wirtschaftsgemeinschaft hinzunehmen, zumal sie aktuell keinen Anhaltspunkt sahen, die 1954 gescheiterten Ansätze wieder aufgreifen zu können. In einer Stellungnahme zur Studie Erhards stimmte er mit dem Wirtschaftsminister darin überein, daß aus der bloßen Kooperation keine organische Einheit, keine Integration, hervorgehen könne. Im Gegensatz zu ihm setzte der Staatssekretär des Auswärtigen aber auf die integrative Wirkung der Brüsseler Institutionen und bezeichnete eine funktionale Integration ohne institutionelle Stütze als undenkbar. Aus einer „funktionellen“ Integration mit „sekundären institutionellen Organen bloß konsultativer Art" konnte seiner Meinung nach keine politische Einigung Europas hervorgehen. So blieb nur die Fortführung der Integration nach dem Muster der EGKS, wobei er Verkehr, Energie und Atomwesen als die gegebenen Sektoren der Erweiterung ansah. Für diesen Weg sprachen seiner Meinung nach nicht nur theoretische Überlegungen, sondern auch die politische Vernunft. Denn einerseits bereiteten die Partner der EGKS entsprechende Schritte vor. Andererseits betrachtete er die Entstehung einer europäischen Volksvertretung mit echten Befugnissen für den „schlechthin entscheidende[n] Punkt“, da die europäische Einigung „von der Einheit der europäischen Völker selbst getragen“ sein mußte. Aber nur die Montanunion besaß ein „europäische[s] Parlament“, wenn auch mit beschränkten Befugnissen. „Hier muß also die weitere politische Entwicklung ansetzen." ${ }^{43}$

\section{Vertikale versus horizontale Integration}

Hallstein hatte trotz klarer Positionsbeschreibung die grundsätzlichen Gegensätze zwischen beiden Integrationsmodellen offensichtlich heruntergespielt. Die unterschiedlichen Standpunkte gewannen aber an Brisanz, als Spaak sich Anfang April, notabene nach der Ratifikation der Pariser Verträge durch die zweite französische Kammer, zum Sprachrohr der Pläne Monnets machte und in Schreiben an Adenauer, Pinay und den italienischen Außenminister Martino eine Außenministerkonferenz der Sechs vorschlug, auf der der Wille zur „relance européenne" durch eine Erweiterung der Zuständigkeiten der EGKS auf die Bereiche Energie und Verkehr sowie durch die Bildung einer Sonderorganisation der EGKS zur friedlichen Nutzung der Atomenergie verkündet werden sollte. Zur praktischen Umsetzung dieses Willens empfahl er die Einberufung einer Delegiertenkonferenz unter dem Vorsitz von Monnet ${ }^{44}$. Die Reaktionen der angesprochenen Regierungen fielen ziemlich uneinheitlich aus. Beyen übersandte seinen Kollegen aus den BENELUX-Staaten nun ein Memorandum, das weit über die Vor-

42 S. Adenauer, Erinnerungen 1955-1959, S. 30.

43 Aufzeichnung Hallstein, 30. 3. 1955, Streng vertraulich, in: BDFD I, S. 582-586, hier S. 582, 585 u. 586; s.a. Küsters, Walter Hallstein, S. $86 \mathrm{f}$.

44 S. PA, BStS, Bd. 350, Spaak an Adenauer, 4. 4. 1955, in französischer Übersetzung in: DDF 1955, Bd. 1, S. 400; Spaak an Pinay, 4. 4. 1955, in: ebd., S. 399; s.a. Spaak, Memoiren, S. 298; vgl. mit falscher Datierung Küsters, Gründung, S. 96. 
schläge Spaaks hinausging. Den Haag lehnte die vertikale Integration von Teilgebieten $a b$ und wartete statt dessen mit einem Gegenentwurf zur Bildung einer supranationalen Gemeinschaft auf. Im Kern ging es ihm dabei um die wirtschaftliche Integration Europas auf dem „Weg über eine Zollunion [bis] zum Zustandekommen einer Wirtschaftsunion". Für diese horizontale Integration hielt Beyen supranationale Behörden von vornherein für unerläßlich ${ }^{45}$.

In Paris warnte man dringend vor überstürzter Eile. Regierung und die Mehrheit der Parlamentarier waren sich zwar darin einig, daß die Pariser Verträge europapolitisch nicht „un point d'arrivée, mais un point de départ“ darstellten. Wollte man aber keinen neuerlichen Fehlschlag riskieren, galt es vier Faktoren in Rechnung zu stellen: die psychologischen Vorbehalte politischer Kreise gegenüber etwaigen Risiken der wirtschaftlichen Integration; die Notwendigkeit zur Berücksichtigung der Überseebesitzungen; die Ausschaltung sämtlicher Konzepte, die zu große Wagnisse heraufbeschworen oder wirtschaftlich nicht gerechtfertigt schienen; die Interessen der Partnerstaaten ${ }^{46}$. Faure sprach sich am 5. 4. vor der Auslandspresse dafür aus, die europäische Politik ohne Dogmatismus fortzusetzen, wobei er vor allem an die Schaffung europäischer Organisationen für das Transportwesen und die Energie unter Einbeziehung der Atomkraft dachte, ohne näher auf den institutionellen Rahmen einzugehen ${ }^{47}$. Eine Woche später revidierte er seine Äußerungen in gewisser Hinsicht, als er auf einer Pressekonferenz die Entscheidung zum Aufbau einer nationalen Atommacht mit dem Hinweis verband, Frankreich halte an einer gewissen Formel europäischer Zusammenarbeit auf dem Atomsektor fest. Die europäische Energie- und Transportorganisation, so fügte er hinzu, müsse nicht unbedingt im Rahmen der EGKS entstehen ${ }^{48}$.

Im Quai d'Orsay zeigte man sich eher an einer koordinierten Energiepolitik denn an Fortschritte bei der Integration des Transportwesens interessiert. Auch der Frage des gemeinsamen Marktes standen die Beamten durchaus aufgeschlossen gegenüber, sofern der Schutz der Außenzölle ausreichend gewahrt bliebe. „En tout état de cause, il peut être préférable de mettre en place un mécanisme qui exerce sur les économies nationales une pression d'ensemble, continue mais très progressive, plutôt que d'isoler tel ou tel secteur. " ${ }^{49}$ Pinay hielt die Vorstellungen Monnets und Spaaks prinzipiell für sinnvoll, aktuell aber für verfrüht. „Faire l'Europe pas à pas et non au galop“, ermahnte er den belgischen Botschafter, der ihm das Schreiben des Außenministers überbrachte ${ }^{50}$. Seine Zurückhaltung erklärt sich insbesondere aus dem Zwang zur Rücksichtnahme auf die unterschiedlichen

45 Memorandum Beyens, 4. 4. 1955, zitiert nach: Spaak, Memoiren, S. 300; s.a. Harryvan/Kersten, Netherlands, S. 139-147.

46 AMAE, DE-CE, Bd. 611, Bl. 15-34, Aufzeichnung der Unterabt. für wirtschaftliche Kooperation im MAE, 14. 4. 1955.

47 Vgl. DDF 1955, Bd. 1, S. 418, Anm. 2.

48 S. Pressekonferenz Faures, 13.4. 1955, in: AdG 1955, S. 5114B; Gerbet, „Relance“ européenne, S. $75 \mathrm{f}$. Küsters legt Faure irrtümlich die Worte in den Mund, Frankreich sei „nicht an einer gewissen formellen europäischen Zusammenarbeit auf dem Sektor der Atomenergie interessiert " $\mathrm{Kü-}$ sters, Gründung, S. 99).

49 Aufzeichnung des MAE, 7. 4. 1955, in: DDF 1955, Bd. 1, S. 418-421, hier S. 421; s.a. AMAE, DECE, Bd. 611, Bl. 15-34, Aufzeichnung der Unterabt. für wirtschaftliche Kooperation im MAE, 14. 4. 1955.

50 Zitiert nach: Gerbet, Construction, S. 168; s.a. Spaak, Memoiren, S. 299. 
Fraktionen im Conseil des Ministres, wo Faure bremste und die Gaullisten eine Erweiterung der EGKS-Kompetenzen gänzlich ablehnten ${ }^{51}$. Außerdem mußte zunächst einmal die „bonne entente franco-allemande“ als "la pierre angulaire de la construction européenne" von den akuten Konfliktstoffen wie der Saarfrage befreit werden. Pinay wandte sich daher am 7.4. an Adenauer und schlug ihm vor, die geplante Außenministerkonferenz der EGKS zu verschieben, um sich Ende April zunächst auf bilateraler Ebene zu verständigen ${ }^{52}$.

Der Kanzler begrüßte grundsätzlich die Idee Spaaks, der europäischen Integration neuen Auftrieb zu geben. Er wollte aber zunächst das Inkrafttreten der Pariser Verträge abwarten und pflichtete der Argumentation Pinays bei, die deutschfranzösische Zusammenarbeit als „Eckpfeiler des europäischen Zusammenschlusses“ könne nur dann tragfähig sein, wenn sie von offenen Problemen entlastet sei. Um Zeit für die notwendigen Verhandlungen zu gewinnen, schlug er in seinen Schreiben an Pinay, Spaak und den Präsidenten des EGKS-Ministerrates, den luxemburgischen Regierungschef Bech, vor, das Treffen der sechs Minister Ende Mai, Anfang Juni durchzuführen ${ }^{53}$. Entscheidungen im Sinne Spaaks hielt er aber auch dann noch für verfrüht. Er empfahl daher zur Vorbereitung späterer Beschlüsse die Einsetzung einer Studienkommission zur Untersuchung der vorliegenden Pläne ${ }^{54}$.

Die gewonnene Zeit galt es nun für die interne Abstimmung zu nutzen. Mit der Bitte um Überprüfung der Vorschläge von Spaak wandte sich der Kanzler am 13. 4. an Erhard und machte ihm unumwunden klar, daß er dessen europapolitische Vorstellungen nicht teilte. Er unterstützte vielmehr die Position Hallsteins, „daß man [...] von der Integration wirklich wichtiger wirtschaftlicher Teilgebiete zu einer Integration auf politischer Ebene kommen kann und wird. Der umgekehrte Weg, der an sich der richtige wäre, ist leider [...] bis auf weiteres unmöglich." 55 Mit Blick auf den seit Jahren schwelenden Streit mit dem Bundeswirtschaftsministerium über den Kurs der Bonner Europapolitik wies er Hallstein gleichzeitig an, die Arbeiten Erhards „im Auge zu behalten“ 56.

Nur einen Tag später legte Monnet den Entwurf einer Erklärung für die auf den 30. 5. terminierte Außenministerkonferen $z^{57}$ vor. Danach bekannten sich die sechs Regierungen zum Ziel der „Bildung der Vereinigten Staaten von Europa auf der Grundlage der Entwicklung gemeinsamer Institutionen, der fortschreitenden Verschmelzung der heute getrennten Volkswirtschaften und einer ständig enger werdenden Assoziierung zwischen Großbritannien und dem Kontinent“. Konkret sah Monnet die Umwandlung der Gemeinsamen Versammlung der EGKS in

51 S. Massigli, Comédie, S. 507; Küsters, Gründung, S. 99.

52 AMAE, Europe 1944-1960, Allemagne, Bd. 389, Bl. 14f., Pinay an Adenauer, 7. 4. 1955; s.a. Laloy an François-Poncet, 7. 4. 1955, in: DDF 1955, Bd. 1, S. 421 f. Zu den deutsch-französischen Saarverhandlungen vgl. Kap. III.3.4.

53 Adenauer an Pinay, 13. 4. 1955, in: Adenauer, Briefe 1953-1955, S. 264 f., hier S. 264; s.a. ders. an Spaak, 13. 4. 1955, in: ebd., S. $267 \mathrm{f}$.

54 S. PA, BStS, Bd. 350, ders. an Bech, 15. 4. 1955.

55 Ders. an Erhard, 13. 4. 1955, in: Adenauer, Briefe 1953-1955, S. 263; s.a. Hentschel, Ludwig Erhard, S. 225; Küsters, Walter Hallstein, S. 88.

56 PA, Abt. 2. Bd. 852, Adenauer an Hallstein, Vermerk, 224-00/13615/55, 13. 4. 1955; zu den innergouvernementalen Auseinandersetzungen vgl. ausführlich: Küsters, Streit.

57 S. ders., Gründung, S. 100. 
ein direkt und allgemein gewähltes Parlament, die regelmäßige Durchführung von Außenministerkonferenzen und die Ausarbeitung von Vertragstexten durch Delegierte vor, mit denen die durch die EGKS begonnene Schaffung gemeinsamer Grundlagen für die wirtschaftliche Entwicklung erweitert würde. Dabei dachte er zunächst an die Gebiete Verkehr, Energie und die friedliche Nutzung der Atomenergie. In einem zweiten Schritt sollte die Delegiertenkonferenz, deren Vorsitz er selbst zu übernehmen gedachte, Programm und Bedingungen für die fortschreitende Gesamtintegration mit dem Ziel der Bildung einer Zollunion untersuchen ${ }^{58}$.

Auf Drängen Spaaks beschlossen die Regierungen der BENELUX-Staaten, sich für Beyens Zollunionsplan mit supranationalen Institutionen einzusetzen. Für den Fall starker Widerstände wollten sie sich aber mit bescheideneren Zielen im Sinne der Überlegungen Monnets begnügen ${ }^{59}$. An der Seine war man von einer derartig klaren Linie noch immer weit entfernt. Wie Pinay am 21. 4. bei einem Besuch an der Themse darlegte, hielt er die Wiederbelebung der Europapolitik allein schon zur Beruhigung der Deutschen für eminent wichtig, sah sich angesichts der parlamentarischen und innergouvernementalen Lage in Paris aber außerstande, große Sprünge zu machen. Anders als sein englischer Kollege Macmillan, der die WEU zum Zentrum des europäischen Aufbaus zu erheben hoffte, hielt Pinay am EGKS-Rahmen fest, zu dem er allerdings nach dem Assoziationsvertrag auch Großbritannien zählte60.

Im Quai d'Orsay erzeugten seine Auffassungen ein geteiltes Echo. Die zuständigen Referenten der Unterabteilung wirtschaftliche Zusammenarbeit warnten vor der Verschärfung des ohnehin schon - insbesondere zugunsten der Bundesrepublik - vorhandenen wirtschaftlichen Ungleichgewichts in der Gemeinschaft. „Si l'Allemagne redevient souveraine et si au surplus elle dispose d'une armée, on ne voit pas bien comment on évitera que l'intégration n'aboutisse à une hégémonie politique aussi bien qu'économique et à la perte de toute liberté de manoeuvre et de toute indépendance diplomatique pour la France."61 Zwei interministerielle Sitzungen, die Ende April zur Abstimmung des französischen Kurses im Quai d'Orsay stattfanden, verliefen ebenfalls alles andere als zur $\mathrm{Zu}$ friedenheit des Außenministers. Pinay selbst hatte dazu die Anregung gegeben, wobei er an ein Treffen hoher Beamter dachte. Faure aber fuhr ihm in die $\mathrm{Pa}$ rade und ordnete an, daß zunächst einmal die Experten der interessierten Ressorts zusammentreffen sollten ${ }^{62}$. Das Ergebnis der tour d'horizon fiel mit den

58 PA, Abt. 2, Bd. 900, Bl. 19-24, „Entwurf einer Erklärung“", 115-104-01/918/55/35, 14. 4. 1955, Streng geheim, Vertraulich (Übersetzung). Zu diesem von Uri redigierten Dokument s.a. Merchant an Dulles, Memorandum, 12. 4. 1955, Confidential, in: FRUS 1955-1957, Bd. 4, S. 279; Bossuat, Jean Monnet, S. 320 f.; Gerbet, „Relance“ européenne, S. $79 \mathrm{f}$.

59 S. Garnier an Pinay, Tel. 188, 26. 4. 1955, Confidentiel, Réservé, in: DDF 1955, Bd. 1, S. 517-519; Spaak, Memoiren, S. 300f.; Küsters, Gründung, S. 100-103.

60 S. Unterredung zwischen Pinay und Macmillan vom 21.4. 1955, in: DDF 1955, Annexes, Bd. 1, S. 23-29; Abkommen über die Assoziation zwischen Großbritannien und der EGKS, 21. 12. 1954, in: EA 1955, S. 7379-7381; zur Zusammenarbeit zwischen Großbritannien und der EGKS vgl. ausführlich Young, Schuman Plan.

61 AMAE, DE-CE, Bd. 611, Bl. 53-58, Aufzeichnung der Unterabt. für wirtschaftliche Zusammenarbeit im MAE, 20.4.1955 (Konzept JPB).

62 Vgl. DDF 1955, Bd. 1, S. 705, Anm. 1. 
Worten des Vorsitzenden der Tagung, René Massigli, „très négatif“ aus ${ }^{63}$. Die Sachverständigen genossen es geradezu, „de verser des seaux d'eau froide sur l'enthousiasme européen des collaborateurs d'Antoine Pinay“64. Ihre Kritik richtete sich vor allem gegen die drohenden Beschränkungen des Ende Dezember 1954 von der Regierung Mendès France initiierten geheimen militärischen Atomprogramms ${ }^{65}$. Insbesondere die Mitarbeiter des Commissariat à l'Energie atomique (CEA) bezeichneten eine Zusammenarbeit im Bereich der Atomenergie als wenig sinnvoll, weil sie sich von den kleinen Partnern in der Sechsergemeinschaft keinen Nutzen erwarteten. Angesichts der restriktiven Haltung der Amerikaner gegenüber den eigenen Kooperationswünschen und der Sonderrolle Englands hielten sie nur die Kooperation mit der Bundesrepublik für interessant $^{66}$. Dabei sahen die Franzosen sich aber einem Dilemma gegenüber. Einerseits lastete seit der Ratifikation der Pariser Verträge auf ihnen der „cauchemar d'un programme atomique germano-américain dépassant le programme française "67. Andererseits befürchteten sie, bei der Gründung einer nuklearen Interessengemeinschaft im Verbund der Sechs oder allein mit der Bundesrepublik einer prädominanten Stellung der Deutschen Paroli bieten zu müssen ${ }^{68}$. Bertrand Goldschmidt, der Directeur des relations extérieures im CEA, und Pierre Guillaumat, Administrateur général des CEA, setzten den Schwerpunkt der Atomenergienutzung eindeutig auf den militärischen Bereich. Da sie um die Schwierigkeiten einer Trennung zwischen ziviler und nicht-ziviler Anwendung wußten, lehnten sie jegliche supranationale Organisation $a b^{69}$, wenngleich sie die Vorteile einer zivilen europäischen Nukleargemeinschaft keineswegs leugneten: Man konnte die Abhängigkeit von den USA abstreifen, Zugang zu den angelsächsischen Kenntnissen erhalten und tiefe Einblicke in die deutsche Atomindustrie gewinnen, ohne sich selbst der Kontrolle im militärischen Sektor zu unterwerfen ${ }^{70}$. Als entschiedener Befürworter der deutsch-französischen Nuklearkooperation trat hingegen der mittlerweile als Conseiller technique im Kabinett Pinays tätige Sauvagnargues auf; er mahnte seine Kollegen, der Bundesrepublik nicht den Eindruck zu vermitteln, „que la France désirerait sous prétexte de coopération, réintroduire des contrôles“. Als Massigli zur Zusammenfassung der verschiedenen nationalen Atominteressen die Gründung eines „Comité directeur de l'industrie atomique en Europe" vorschlug, legte sich Guillaumat prompt quer: Ein solches Organ sei ähnlich gefährlich wie ein Atompool. Auch in den anderen zur Diskussion stehenden Kooperationsbereichen, etwa dem Luftransportwesen oder der konventionellen Energie, sahen die Experten kaum erfolgversprechende Ansätze ${ }^{71}$.

63 AMAE, DE-CE, Bd. 611, Bl. 67-77, Interministerielle Treffen vom 22. u. 25. 4. 1955.

64 Massigli, Comédie, S. 506, Anm. 1.

$65 \mathrm{Vgl}$. Kap. III.4.4.

66 AMAE, DE-CE, Bd. 611, Bl. 67-77, Interministerielle Treffen vom 22. u. 25. 4. 1955.

67 Guillen, La France et la négociation des traités de Rome, S. 514.

68 S. Aufzeichnung des MAE, o.D., in: DDF 1955, Bd. 1, S. 547.

$69 \mathrm{Vgl}$. Guillen, La France et la négociation du traité d’Euratom, S. 395; Goldschmidt, Rivalités, S. 209-213.

70 Vgl. Weilemann, Anfänge, S. 41.

7 AMAE, DE-CE, Bd. 611, Bl. 67-77, Interministerielle Treffen vom 22. u. 25. 4. 1955; s.a. Aufzeichnung des MAE, o.D., in: DDF 1955, Bd. 1, S. 546-551. 
François Valéry, Leiter der Unterabteilung wirtschaftliche Zusammenarbeit im Quai d'Orsay, war mit diesem Ergebnis so unzufrieden, daß er die Prinzipien der französischen Haltung zur "relance européenne" noch einmal in zwei Aufzeichnungen zusammenfaßte. Im Gegensatz zum gesamtwirtschaftlichen Konzept der BENELUX-Staaten konnte es seines Erachtens für Frankreich bei der Ausweitung der europäischen Politik vorerst nur um einen sektoralen Zugang gehen. Dabei sah er reelle Chancen einer "association" in den Bereichen Transport und Atomenergie ${ }^{72}$, ohne aber rasche Ergebnisse zu erwarten. Mit Blick auf die bevorstehende Außenministerkonferenz ging er davon aus, daß allenfalls allgemeine Richtlinien zur Ausdehnung und Prozedur der neuen Maßnahmen getroffen werden könnten. Eine Arbeitsgruppe mußte dann Wege zur Assoziation suchen, wobei die Diskussion auch Großbritannien offenstehen sollte ${ }^{73}$.

Angesichts der innerfranzösischen Hemmnisse konnte sich Pinay nur mit äußerster Behutsamkeit bewegen. Ende April traf er mit Adenauer zusammen, um nach der Ausräumung letzter Schwierigkeiten in der Saarfrage und bei der Hinterlegung der Ratifikationsurkunden zu den Pariser Verträgen ${ }^{74}$ sich mit ihm über den Fortgang der Europapolitik abzustimmen. Das Ergebnis fiel recht ernüchternd aus. Als Adenauer sich für die Aufnahme von Beratungen über eine gemeinsame friedliche Nutzung der Kernenergie und im Verkehr aussprach, mußte Pinay zugeben, daß Faure beide Sektoren außerhalb des Rahmens der EGKS angesiedelt zu sehen wünschte. Ihm selbst schwebte daher vor, die Dinge möglichst pragmatisch anzugehen und auf einigen Gebieten zu zweit, auf anderen zu sechst oder in noch größerem Rahmen zusammenzuarbeiten. In Anlehnung an seinen Plan vom Februar schlug er regelmäßige Treffen des EGKS-Ministerrates alle sechs bis acht Wochen sowie die Schaffung eines Sekretariats vor. Obwohl der Kanzler darauf nicht einging ${ }^{75}$, läßt ein zur Vorbereitung der Unterredung vorbereitetes Dokument des Auswärtigen Amtes erkennen, daß die Bundesregierung sehr wohl diesen Gedanken aufzunehmen bereit war. Darüber hinaus zielte sie im Bereich der horizontalen Integration auf eine engere zollpolitische Verbindung, während währungspolitische Fragen vorerst beiseite gelassen werden sollten. In der vertikalen Richtung, der Integration der Sechs auf speziellen Gebieten, stand die Atomwirtschaft im Vordergrund des Interesses, wohingegen die Gründung supranationaler Behörden im Transport- und Energiewesen als vorläufig illusorisch galt. Die politische Konzeption der regelmäßigen Außenministerkonferenzen, wie Pinay sie entwickelt hatte, war mittlerweile von Monnet aufgenommen worden. Das Thema Direktwahl zur Gemeinsamen Versammlung wollte Pinay indes bis zur französischen Wahl aufschieben ${ }^{76}$.

72 AMAE, DE-CE, Bd. 611, Bl. 100-107, Aufzeichnung der Unterabt. für wirtschaftliche Kooperation im MAE, 2. 5. 1955 (Konzept FV).

73 S. ebd., Bl. 86-90, Aufzeichnung Valéry, 27. 4. 1955.

74 Vgl. Kap. III.3.4. u. III.4.4.

75 S. BA, NL Blankenhorn, Bd. 45b, Bl. 2-20, Unterredung zwischen Adenauer und Pinay vom 29. 4. 1955, Niederschrift, Streng geheim. Pinay hat seinen Plan des Europäischen Staatenbundsrates entgegen der Darstellung von Küsters nicht ausführlich behandelt (Küsters, Gründung, S. $104 \mathrm{f}$.).

76 S. PA, Abt. 2, Bd. 900, Bl. 25-29, Aufzeichnung, o.D. 
Mitte Mai präsentierten die BENELUX-Staaten dann ein gemeinsames Memorandum, mit dem sie die Ausweitung der sektoralen Integration mit der Errichtung eines Gemeinsamen Marktes verbanden. In weiten Teilen stimmte das Dokument mit dem Vorschlag Monnets vom 14. 4. überein, wobei aber bezeichnenderweise nicht von den Vereinigten Staaten von Europa die Rede war und sein Name als potentieller Präsident der Delegiertenkonferenz fehlte ${ }^{77}$. Frankreich hielt die Ausführungen des Memorandums zur sektoralen Integration insgesamt für annehmbar. Es akzeptierte multilaterale Verträge zur Atomenergie mit dem Ziel einer internationalen, nicht supranationalen Organisation, die nicht auf die Sechsergemeinschaft beschränkt bleiben und nationale Programme unangetastet lassen sollte. Auch eine gewisse Ausdehnung der EGKS-Kompetenzen auf die klassische Energie betrachtete man als diskutabel. Die Vorschläge zum Transportwesen gedachte man hingegen eher im Rahmen der Europäischen Konferenz der Transportminister abzuhandeln. Den größten Widerstand riefen erwartungsgemäß die Vorstellungen der BENELUX-Staaten zur wirtschaftlichen Kooperation hervor. Gewiß spielte dabei der „complexe d'infériorité" ${ }^{\text {"78 }}$ gegenüber dem wirtschaftlich starken Nachbarn im Osten eine Rolle. Denn mit dem Gemeinsamen Markt wären die französischen Grenzen für die europäische und globale Konkurrenz geöffnet worden, was für die protektionistisch orientierte französische Wirtschaft unannehmbar schien. Wie sollte ein gemeinsamer Zolltarif aussehen, wenn die Niedrigzolländer wie die BENELUX-Staaten forderten, ihren Tarif zugrunde zu legen, und Hochzollstaaten wie Frankreich alles beim alten belassen wollten. Außerdem warf der Plan kaum lösbare Probleme hinsichtlich der Überseegebiete auf. Eine vollständige Ablehnung kam aber aus allgemeinpolitischen Erwägungen nicht in Frage. Der Quai d'Orsay regte daher an, auf der Außenministerkonferenz eine intensive Prüfung des Vorschlags in einem periodisch stattfindenden Rat der Außenminister, einem Komitee der Ständigen Vertreter sowie einem Sekretariat zu empfehlen. Allein zur Atomfrage schwebte dem Ministerium eine rasch einzuberufende Konferenz vor ${ }^{79}$.

Ende Mai verknüpften sich die innerfranzösischen Meinungsverschiedenheiten über die Weiterentwicklung der Europapolitik mit der Frage der Nachfolge Monnets als Präsident der Hohen Behörde. Die Bundesregierung, die seinen Rücktritt mit Bedauern aufgenommen hatte ${ }^{80}$, plädierte für die Wahl eines Vertreters der kleinen EGKS-Staaten, um deren Ängste vor der Marginalisation durch die GroBen zu mindern. Sie verweigerte daher auch dem internen Votum der Hohen Behörde, die sich für die Beförderung des deutschen Vizepräsidenten Franz Etzel ausgesprochen hatte, die Zustimmung. Den Posten abermals einem Franzosen zu

77 S. Memorandum der BENELUX-Staaten an die Mitglieder der EGKS, übermittelt am 18.5. 1955, in: L'Année politique 1955, S. 714-716; eine deutsche Zusammenfassung in: AdG 1955, S. 5189B; zur Entstehung vgl. Harryvan/Kersten, Netherlands, S. 146-152.

78 Artikel Courtins, in: „Réforme“, 30.3. 1957, im Auszug auch in: BDFD III, S. 493-498, hier S. 484.

79 S. Aufzeichnung des MAE, Mai 1955, in: DDF 1955, Bd. 1, S. 703-707; Aufzeichnung der Abt. für wirtschaftliche und finanzielle Angelegenheiten im MAE, 18.5. 1955, in: ebd., S. 665-670; Aufzeichnung des MAE, 26. 5. 1955, in: ebd., S. 692 f.

80 S. AMAE, Europe 1944-1960, Généralités, Bd. 115, Bl. 179, François-Poncet an MAE, Tel. 5638/ 43, 16. 11. 1954, Réservé; Hollmann, Nachfolge, S. $189 \mathrm{f}$. 
übertragen, wollte sie nur dann, wenn es sich um eine „Persönlichkeit von überragender europäischer Bedeutung “ wie Robert Schuman handelte ${ }^{81}$.

Der deutsche Altruismus war den Franzosen völlig fremd. Die Spitzenpositionen in den europäischen Organisationen lockten mit Einfluß und Prestige, und so schickten sie den früheren Regierungschef Ramadier ins Rennen. Dessen politische Statur reichte Adenauer aber auf keinen Fall aus ${ }^{82}$. Als der Quai d'Orsay an der Kandidatur festhielt, erklärte der Kanzler sie dem französischen Hohen Kommissar gegenüber am 25. 3. unverblümt für aussichtslos ${ }^{83}$. Daraufhin brachte der Matignon mit René Mayer einen weiteren ehemaligen Président du Conseil ins Gespräch, der sein Interesse allerdings zurückzog, nachdem Monnet ihm zu verstehen gegeben hatte, er wolle doch im Amt bleiben ${ }^{84}$. Aus Sorge um den Erhalt seines Kabinetts sprach sich Faure Anfang Mai auf einer Konferenz der sechs Außenminister gegen eine Verlängerung der Amtszeit des Präsidenten aus. Während er in seinen Memoiren Glauben machen will, man habe sich einstimmig auf René Mayer als Nachfolger Monnets verständigt ${ }^{85}$, zauberte Faure nun den ehemaligen Industrie- und Handelsminister Jean-Marie Louvel als neuen Kandidaten aus dem Hut, ein in der Presse schon seit Wochen gehandelter Name ${ }^{86}$. Der von Spaak angeregten Bewerbung Mayers stand er skeptisch gegenüber, weil dessen Abgeordnetenmandat im algerischen Constantine gerade erst verlängert worden war. Adenauer verhielt sich im Kreis der Minister rezeptiv, äußerte sich aber Hallstein gegenüber nicht abgeneigt, der Wahl Louvels zuzustimmen ${ }^{87}$. Im Gegensatz zur späteren Behauptung Faures, Adenauer sei Monnet gegenüber „résolument hostile" eingestellt gewesen ${ }^{88}$, hoffte der Kanzler insgeheim immer noch darauf, den Präsidenten im Amt halten zu können ${ }^{89}$. Obwohl er wußte, daß Faure Mayer am Vortag im Kabinett als seinen Nachfolger vorgeschlagen hatte ${ }^{90}$, erklärte Monnet am 21. 5. in einem Schreiben an Adenauer offiziell seine Bereitschaft, die Präsidentschaft weiterzuführen ${ }^{91}$. Um dem Vorstoß Nachdruck zu verleihen, lancierte er den Brief in die französische Presse ${ }^{92}$.

Das letzte Wort lag nun beim Conseil des Ministres, der nur zu genau wußte, mit dem Urteil über Monnet auch eine Entscheidung über die Zukunft der europäischen Integration zu treffen. Und die war höchst umstritten. Das MRP mit Schuman und Teitgen an der Spitze forderte die Regierung in einer Resolution zu

81 PA, BStS, Bd. 350, Hallstein an Adenauer, Notiz, 10.1. 1955; s.a. Hollmann, Nachfolge, S. 190192.

82 S. Faure an Bonn etc., Tel. 382/85 etc., 22. 1. 1955, in: DDF 1955, Bd. 1, S. 110 f.; PA, BStS, Bd. 350, Adenauer an Spaak, 3. 2. 1955.

83 S. BA, NL Blankenhorn, Bd. 44b, Bl. 80, Aufzeichnung, 25.3. 1955.

84 S. ebd., Bd. 45b, Bl. 2-20, Unterredung zwischen Adenauer und Pinay vom 29. 4. 1955, Niederschrift, Streng geheim.

85 S. Faure, Mémoires, Bd. 2, S. 211; zum Verhältnis Faures zu Monnet s. ebd., S. 211-215; vgl. Gerbet, "Relance“ européenne, S. 86.

$86 \mathrm{Vgl}$. Hollmann, Nachfolge, S. $192 \mathrm{f}$.

87 S. PA, BStS, Bd. 350, Hallstein an Vertretung beim Europarat, Tel. 25, 13. 5. 1955.

88 Faure, Mémoires, Bd. 2, S. 210; s.a. Gerbet, „Relance“ européenne, S. 84 f.

89 S. BA, NL Blankenhorn, Bd. 45b, B1.2-20, Unterredung zwischen Adenauer und Pinay vom 29. 4. 1955, Niederschrift, Streng geheim.

$90 \mathrm{Vgl}$. Küsters, Gründung, S. $109 \mathrm{f}$.

91 S. PA, BStS, Bd. 350, Monnet an Adenauer, 21. 5. 1955 (Übersetzung); Gerbet, René Mayer, S. 96.

92 Vgl. AdG 1955, S. 5190; Küsters, Gründung, S. 110. 
der von Monnet gewünschten Erweiterung der Montanunion auf ${ }^{93}$. Die gaullistschen Feinde der europäischen Integration im Kabinett, zugleich Gegner Monnets, wie Gaston Palewski, Pierre Koenig und Edouard Corniglion-Molinier, widersetzten sich diesem Konzept, weil sie der deutschen Wirtschaftskraft die Tendenz zur Dominanz Europas unterstellten. Im Außenpolitischen Ausschuß der Assemblée Nationale verlangte der gaullistische Abgeordnete Vendroux nun eine sofortige Debatte des Parlaments mit dem Ziel, die Montanunion auf die bisherigen Aufgaben zu beschränken, konnte sich aber nicht durchsetzen, da die Sozialisten sich der Stimme enthielten ${ }^{94}$. Aus Sorge vor der Kabinettsspaltung kürte Faure mit Zustimmung der Minister nun Mayer zum Nachfolger Monnets, wobei Louvel als Ersatzmann im Rennen blieb. Am 27. 5. teilten die Franzosen den Verbündeten die Nominierung mit ${ }^{95}$.

Um die Verstimmung der Partner zu dämpfen, gab der französische Regierungschef auf einer Pressekonferenz gleichzeitig die Bereitschaft bekannt, Beratungen über eine gemeinsame Organisation für das Transportwesen und Energie auf Regierungsebene aufzunehmen". Das bedeutete aber noch lange nicht ein Einlenken auf das Konzept Monnets oder Spaaks. Wie der Quai d'Orsay nämlich gegenüber der Deutschen Botschaft darlegte, war man zwar bereit, das Memorandum der BENELUX-Staaten als Verhandlungsgrundlage für die Außenministerkonferenz zu akzeptieren. Die Regierung verlangte aber aus Rücksicht auf die Gaullisten, die „relance“ nicht zu stark auf die Sechsergemeinschaft zu konzentrieren. Auf dem Atomsektor wollte sie eine Zusammenarbeit in einer Weise eingehen, so daß „praktisch von einer Integration die Rede sein“ könne. Auf dem Gebiet der Verkehrsfragen zielte sie hingegen auf die Intensivierung der Zusammenarbeit im Rahmen der bestehenden Transportministerkonferenz, um auch andere Staaten wie die Schweiz, Dänemark oder Österreich zu beteiligen. Besonders reizvoll wirkte auf Frankreich die Zusammenarbeit in der Luftfahrt, während es der allgemeinen wirtschaftlichen Integration weiterhin größte Bedenken entgegen brachte, da ein „schrankenloser Wirtschaftsliberalismus gewisse Gebiete zu Gunsten anderer wirtschaftlich und sozial verelenden" ließe. Als Conditio sine qua non forderte man die Einigung auf einen gemeinsamen Außenzoll der Sechs, der einen ausreichenden Schutz für die europäische Industrie und Landwirtschaft gewährleisten würde ${ }^{97}$.

In der Bundesrepublik waren sich die Politiker weder in der Causa Monnet noch in der grundsätzlichen Ausrichtung der Europapolitik einig. Adenauer ließ in Paris wissen, er unterstütze Monnet ${ }^{98}$. Der nicht selbst zum Zuge kommende Etzel sprach sich bei einer Doppelkandidatur Louvel gegen Mayer für letzteren aus, weil er ihn als „kraftvolle“ Persönlichkeit und „aktiven Europäer“ schätzte"

93 Zur Resolution des MRP-Kongresses vom 19.-22. 5. 1955 vgl. Brunet, MRP, S. 237 f.; zur Haltung der Partei gegenüber dem Gemeinsamen Markt vgl. Irving, Christian Democracy, S. 188-194.

94 Vgl. Küsters, Gründung, S. $111 \mathrm{f}$.

95 S. Pinay an Bonn etc., Tel. 2469 etc., 27. 5. 1955, in: DDF 1955, Bd. 1, S. 693; AdG 1955, S. 5190.

96 Vgl. Küsters, Gründung, S. 112.

97 PA, Ref. 200, AZ 85.11\%, Bd. 1, von Walther an AA, FS Nr. 312, 27. 5. 1955, Citissime.

98 S. AMAE, Europe 1944-1960, Généralités, Bd. 115, Bl. 253, François-Poncet an MAE, Tel. 2080, 27. 5. 1955, Réservé.

99 PA, BStS, Bd. 350, Etzel an Adenauer, 28. 5. 1955, Streng vertraulich. 
Während sich im Auswärtigen Amt die Überzeugung festigte, daß die Monnetschen Pläne unter den gegebenen Umständen noch die beste Gewähr böten, à la longue eine institutionelle Integration verwirklichen zu können, lehnte das Bundeswirtschaftsministerium weitere Teilintegrationen ab. Allerdings waren sich auch die Beamten in Duisdorf nicht vollständig einig. Von der Groeben akzeptierte eine regionale Zollunion unter den Sechsen mit starken Institutionen als ersten Schritt zu einer Freihandelsordnung. Erhard fürchtete die Entwicklung zu einem regional abgeschlossenen Handelskreislauf und zielte statt dessen auf ein Freihandelssystem über einen intensivierten Handelsaustausch ohne weitere institutionelle Absicherung ${ }^{100}$. Er machte sich damit zum Wortführer jener Wirtschaftskreise, die die Vorteile der Liberalisierung eines Binnenmarktes durch die Errichtung eines gemeinsamen Außenzolls mit deutlich steigenden Tarifen schwinden sahen, wohlwissend, daß die deutsche Wirtschaft vornehmlich mit den Staaten außerhalb der Sechsergemeinschaft handelte: 75\% des bundesdeutschen Exports gingen 1955 nicht in die Staaten der EGKS, und nur 28\% der Einfuhren kamen von dort ${ }^{101}$.

Zur Festlegung der deutschen Position für die bevorstehende Außenministerkonferenz traf sich Erhard am 22. 5. mit Etzel, der zu den Ansätzen des Auswärtigen Amtes und des Wirtschaftsministeriums noch eine weitere Variante hinzufügte ${ }^{102}$, und dem künftigen Außenminister von Brentano sowie diversen Mitarbeitern. Am Ende einer sehr offenen, den bestehenden Dissens in der Frage der institutionellen Ausgestaltung aber nicht vertiefenden Diskussion einigte sich die Runde, ein Memorandum über die Bildung eines Gemeinsamen Marktes mit dem Kern einer Zollunion zu verfassen. Prinzipiell lag den Beschlüssen das Konzept der funktionalen, aber durch ein institutionelles Gefüge ergänzten Integration zugrunde, das sich auf alle Bereiche erstreckte, die nicht von der Montanunion erfaßt wurden ${ }^{103}$.

Die Haltung des Wirtschaftsministeriums, aber auch des Landwirtschaftsministeriums unter Heinrich Lübke blieb eindeutig ablehnend gegenüber der Ausdehnung des Prinzips der sektoralen Integration. Auch die deutsche Industrie machte keinen Hehl aus ihrer Abneigung und führte mit Hilfe der von den großen Wirtschaftsorganisationen inspirierten Presse mittlerweile einen scharfen Kampf gegen die etwaige Erweiterungen der Montanunion ${ }^{104}$. Nachdem Auswärtiges Amt und Bundeswirtschaftsministerium gemeinsam einen Entwurf für das Memorandum erarbeitet hatten, kam es am 26. 5. zu einer neuerlichen Zusammenkunft der beteiligten Ressorts. Hallstein hatte am Tag zuvor bei einer Besprechung mit Adenauer auf Bühler Höhe eine ziemlich rigide Weisung des Kanzlers erhalten: Unterstützung der Wiederwahl Monnets als Präsident der Hohen Behörde,

$100 \mathrm{Vgl}$. Küsters, Gründung, S. 114.

$101 \mathrm{Vgl}$. Loth, Europakonzeptionen, S. 594.

102 S. Aufzeichnung Etzel, 22. 4. 1955, in: BDFD II, S. 731-738. Zum Konflikt zwischen Etzel und Erhard über die Ausrichtung der deutschen Europapolitik vgl. ausführlich: Enders, Integration, hier S. 148-150; s.a. Küsters, Gründung, S. $115 \mathrm{f}$.

${ }^{103}$ Zum Treffen im Landhaus Müller-Armacks in Eicherscheid s. von der Groeben, Deutschland, S. 273 f.; Müller-Armack, Weg, S. 99 f.; Küsters, Gründung, S. 116-118.

${ }^{104}$ S. Artikel Lübkes, in: „General-Anzeiger“, 17. 5. 1955, auch in: BDFD II, S. 738-740; FrançoisPoncet an Pinay, Nr. 209, 25. 5. 1955, in: DDF 1955, Bd. 1, S. 683-686. 
aber Ablehnung dessen Vorschläge zur Ausdehnung der Kompetenzen der Gemeinschaftsorgane ${ }^{105}$. Der Verlauf der Diskussion in der Koblenzer Straße zeigte klar, daß die Meinungsunterschiede weiterhin nicht ausgeräumt waren. Wie Ophüls als Vorsitzender formulierte, ging es zunächst einmal darum, die Außenministerkonferenz erfolgreich durchzuführen, galt sie doch in seinen Augen als letzte Chance, den Europagedanken in "politische Realität“ umzuwandeln. Eine endgültige Ausformulierung des deutschen Standpunktes hatte dahinter zurückzustehen und sollte erst nach der Konferenz erfolgen ${ }^{106 .}$

\section{Bescheidener Neubeginn in Messina}

Am 1. 6. begann die Tagung der sechs Außenminister im sizilianischen Messina, der Heimat des italienischen Delegationsleiters Martino ${ }^{107}$. Nach der Begrüßung durch den Vorsitzenden Bech und Gastgeber Martino zogen sich die Minister zur privaten Besprechung zurück, um die Frage der Nachfolge Monnets zu klären. Der hatte mittlerweile den Rückzug angetreten und erklärt, er stünde für das Amt des Präsidenten der Hohen Behörde nun doch nicht mehr zur Verfügung. Die Schuld dafür schob er merkwürdigerweise nicht dem Beschluß der französischen, sondern der deutschen Regierung in die Schuhe. Denn das ihm von Etzel vorab im Entwurf gegebene deutsche Memorandum lief seiner Meinung nach auf eine bloße wirtschaftliche Kooperation souveräner Staaten hinaus, und Monnet war nicht bereit, sich und die Hohe Behörde einer solchen Europapolitik zu unterwerfen ${ }^{108}$. Somit lag nur noch ein Hut im Ring, der von Mayer. Adenauer wollte dessen Ernennung aber offenbar nicht so ohne weiteres zustimmen. In seinem Auftrag stellte Hallstein, der ihn vertrat, weil der Kanzler sein Doppelamt mittlerweile aufgegeben hatte, der neue Außenminister aber noch nicht in die Koblenzer Straße eingezogen war ${ }^{109}$, die Frage nach der Nationalität des künftigen Chefs der Hohen Behörde und machte sich damit zum Sprachrohr jener Stimmen, die eine Rotation bei der Bestallung des Präsidenten befürworteten. Wie nicht anders zu erwarten, verteidigte Pinay mit Verve den französischen Personalvorschlag. Um den beiden Kontrahenten die Chance zu geben, das Gesicht zu wahren, einigten sich die Minister schließlich im Grundsatz darauf, stets die meistqualifizierte Person ungeachtet der Nationalität zu wählen, aber keinem Mitglied ein Monopolrecht einzuräumen. Anschließend ernannten sie Mayer einstimmig zu ihrem Favoriten und gaben nach telephonischer Einwilligung der Hohen Behörde am folgenden Tag seine Ernennung bekannt ${ }^{110}$.

105 S. BA, NL Blankenhorn, Bd. 41b, Bl. 56-62, Unterredung zwischen Adenauer und Blankenhorn, von Herwarth, Krekeler, von Maltzan und Hallstein vom 25. 5. 1955; Küsters, Walter Hallstein, S. 89.

106 PA, Abr. 2, Bd. 900, Bl. 100-105, Ressortbesprechung im Auswärtigen Amt vom 26. 5. 1955.

107 Zur Konferenz von Messina s. PA, Abt. 2, Bd. 901, Bl. 23-97, Konferenz der EGKS-Außenminister vom 1./2.6. 1955, MAE 11/55, 13.6. 1955, Entwurf; Pinay an diplomatische Vertretungen, Zirkulartel. 49, 10. 6. 1955, in: DDF 1955, Bd. 1, S. 756-758; aus der Memoirenliteratur: Beyen, Spel, S. 238 f.; Müller-Armack, Weg, S. 101-103; Pineau/Rimbaud, Grand Pari, S. 169-177; Spaak, Memoiren, S. 302-306; auf archivalischer Basis zusammenfassend: Küsters, Gründung, S. 119-127.

108 S. PA, Abt. 2, Bd. 902, Bl. 119-123, Monnet an Adenauer, 31. 5. 1955; ebd., Bl. 121-123, ders. an Etzel, 31. 5. 1955; Enders, Integration, S. 151.

$109 \mathrm{Vgl}$. Küsters, Walter Hallstein, S. $88 \mathrm{f}$.

110 S. PA, Abt. 2, Bd. 901, Bl. 23-97, Konferenz der EGKS-Außenminister vom 1./2.6. 1955, MAE 
Am Morgen des 2.6. begann dann die Diskussion über den zentralen Tagesordnungspunkt, das Aktionsprogramm für die Entwicklung der europäischen Integration. Beyen hatte die Aussprache am Vorabend mit Erläuterungen zum BENELUX-Memorandum eingeleitet. Martino legte nun zur Darlegung des italienischen Standpunktes ein eigenes Memorandum vor, das trotz erheblicher Bedenken gegenüber der sektoralen Integration die Bereitschaft erklärte, im Bereich des Transportwesens und der Energie Möglichkeiten einer intensiveren Zusammenarbeit zu studieren. Den Schwerpunkt legte er aber auf die schrittweise Verwirklichung des Gemeinsamen Marktes, der sich auf das gesamte wirtschaftliche und soziale Leben der Mitgliedsstaaten erstrecken sollte ${ }^{111}$.

Nach Martino ergriff Hallstein, der mit einer formellen „Ermächtigung“ Adenauers angereist war ${ }^{112}$, das Wort. Er bot ein beeindruckendes Plädoyer für die europäische Einigung als „wesentlichste[s] Fundament für eine Ost-Westverständigung“. Ohne Gleichgewicht zwischen den Blöcken sei der Weltfrieden gefährdet, ohne europäische Einigung dieses Gleichgewicht aber nicht zu erreichen. Ausgangspunkt jeder weiteren Integration, so führte er nicht zuletzt den Franzosen vor Augen, müsse die Sechsergemeinschaft sein. Aber natürlich wünsche er sich auch eine „wirkliche Mitarbeit Großbritanniens“113. Nach diesen Präliminarien stellte der Staatssekretär das deutsche Memorandum vor. Er unterstützte den BENELUX-Vorschlag einer Koordinierung der europäischen Verkehrs- bzw. Energiepolitik unter der Leitung des EGKS-Ministerrates und zeigte besonderes Interesse an der gemeinsamen Erforschung bzw. Nutzung der Kernenergie, der er über die wirtschaftlichen Vorteile hinaus auch große politische Bedeutung beimaß. Im Mittelpunkt des Dokuments stand die allgemeine wirtschaftliche Integration, die durch eine weitgehende Beseitigung der Hemmnisse im Wirtschaftsverkehr angestrebt wurde: Liberalisierung des Warenverkehrs, Abbau der Zölle, Liberalisierung des Kapital- und Dienstleistungsverkehrs, Freizügigkeit innerhalb der Gemeinschaft. Zur Erleichterung der Umstrukturierung schlug Hallstein Übergangs- und Anpassungsmaßnahmen sowie einen Kapitalfonds zur Investitionsförderung vor. Auf die von den BENELUX-Staaten angeregte Errichtung supranationaler Organe ging das deutsche Memorandum nicht ein, schloß sie aber auch nicht aus. Zur Umsetzung der empfohlenen Maßnahmen schlug die Bundesregierung vor, unter der Verantwortung des EGKS-Ministerrates ein ständiges Konsultativorgan mit der Aufgabe zu betrauen, Regeln für die wirtschaftliche Zusammenarbeit aufzustellen. Einzelheiten sollte eine Regierungskonferenz der EGKS-Mitglieder ausarbeiten ${ }^{114}$.

11/55, 13. 6. 1955, Entwurf; AMAE, Europe 1944-1960, Généralités, Bd. 115, Bl. 257-258, François-Poncet an MAE, Tel. 2140, 2.6. 1955; Kommuniqué in: AdG 1955, S. 5190 ; Gerbet, René Mayer, S. 97; Hollmann, Nachfolge, S. 200 f.

${ }^{11} \mathrm{~S}$. Memorandum der italienischen Delegation, 1.6. 1955 in: L'Année politique 1955, S. $717 \mathrm{f}$.; in deutscher Übersetzung im Auszug in: AdG 1955, S. 5190; vgl. Serra, L'Italia.

112 S. PA, Abt. 2, Bd. 900, Bl. 56 f., Ermächtigung Adenauers, o.D.

113 Ebd., Bd. 901, Bl. 23-97, Konferenz der EGKS-Außenminister vom 1./2.6. 1955, MAE 11/55, 13. 6. 1955, Entwurf, im Auszug in: BDFD II, S. 752-755, hier S. 753.

114 S. Memorandum der deutschen Delegation, 1.6. 1955, in: ebd., S. 749-751; PA, Abt. 2, Bd. 902, Bl. 164, Ophüls an Calmes, FS AZ 225-00/10.190/55, 3. 9. 1955; Küsters, Gründung, S. $118 \mathrm{f}$. 
Nun ergriff Spaak für das Dreier-Memorandum Partei und ergänzte es mit dem Verfahrensvorschlag, zunächst eine Sachverständigenkonferenz einzuberufen, deren Arbeiten von einer "politischen Persönlichkeit koordiniert" werde115. Anschließend sprach Pinay. Als einziger Delegationsleiter legte er kein schriftliches Dokument vor, was um so bemerkenswerter war, als Frankreich die letzten beiden europapolitischen Großprojekte, Montanunion und Europaarmee, bewußt selbst initiiert und durch Arbeitsvorlagen maßgeblich zu beeinflussen versucht hatte. Nun aber, nach den katastrophalen Erfahrungen mit dem Pleven-Plan, wollte die französische Regierung wohl ihre Handlungsspielräume nicht einengen. Wie nicht anders zu erwarten war, sprach sich Pinay für die Notwendigkeit der Fortsetzung der europäischen Zusammenarbeit aus. Aber er ermahnte sofort ausdrücklich dazu, „auf dem Boden der praktischen Möglichkeiten zu bleiben“. Und das bedeutete nichts anderes als die sektorale Integration im Verkehrswesen und auf dem Energiesektor unter Einschluß der Atomenergie. Eine allgemein-wirtschaftliche Integration im Sinne der Niederlande oder der Bundesrepublik kam für Frankreich vorläufig nicht in Frage. Vor der Schaffung eines Gemeinsamen Marktes mußten seiner Meinung nach zunächst Untersuchungen über den Schutz der Gemeinschaft gegenüber Dritten, die schrittweise Abstimmung der geltenden Sozialgesetzgebung, die Verhinderung einer Vertiefung der sozialen Gegensätze und die Ausschließung von gewissen Maßnahmen bei der Währungskonvertierung durchgeführt werden. Auch das von den Partnern angeregte Procedere gefielt dem Minister nicht. Er warnte vor der übereilten Einberufung einer Konferenz und plädierte statt dessen für die Einsetzung einer Art ständiger Organisation, wie er es mit seinem alten Vorschlag der regelmäßig tagenden Außenministerkonferenz bereits formuliert hatte ${ }^{116}$.

Pinay bemerkte sofort, welch „negativ[en]“ Eindruck seine Ausführungen hervorriefen. Deshalb bemühte er sich nach der Mittagspause nach Kräften, seinen Standpunkt noch einmal zu verdeutlichen ${ }^{117}$. Der Erfolg blieb mäßig. Schließlich wurde die Veranstaltung erneut unterbrochen, um den Delegationen Zeit für die Abfassung einer Schlußresolution zu geben. Die größten Schwierigkeiten verursachte begreiflicherweise der Passus über die allgemeine wirtschaftliche Integration. Die BENELUX-Staaten wollten den entsprechenden Teil aus ihrem Memorandum übernehmen. Frankreich und die Bundesrepublik legten einen gemeinsamen Gegenentwurf vor, der in Anlehnung an die Ausführungen Pinays vom Vormittag vor der schrittweisen Einführung eines Gemeinsamen Marktes Untersuchungen über die Vereinheitlichung des Zollsystems hinsichtlich Dritter, die Harmonisierung der Sozialpolitik und der Arbeitsbedingungen, die Schaffung eines Europäischen Investitionsfonds und die Annahme von Methoden für eine weitreichende Koordinierung der gemeinsamen Währungspolitik vorsah ${ }^{118}$. Nach

115 PA, Abt. 2, Bd. 901, Bl. 23-97, Konferenz der EGKS-Außenminister vom 1./2.6. 1955, MAE 11/ 55, 13. 6. 1955, Entwurf; s.a. Harryvan/Kersten, Netherlands, S. 153-156.

116 PA, Abt. 2, Bd. 901, Bl. 23-97, Konferenz der EGKS-Außenminister vom 1./2.6. 1955, MAE 11/ 55, 13. 6. 1955, Entwurf, im Auszug in: BDFD II, S. 755-757, hier S. 755; s.a. Guillen, Wiederaufschwung, S. $4 \mathrm{f}$.

117 PA, Abt. 2, Bd. 901, Bl. 23-97, Konferenz der EGKS-Außenminister vom 1./2.6. 1955, MAE 11/ 55, 13. 6. 1955, Entwurf.

118 S. ebd., Bl. 85, Anlage VII zum Protokollentwurf, o.D. 
der Wiederaufnahme der Diskussion wehrte sich Spaak entschieden gegen etwaige „Vorbedingung[en]“ und monierte in der Aufzählung des deutsch-französischen Papiers das Fehlen der Einsetzung einer gemeinsamen Behörde mit den zur Verwirklichung der gesetzten Ziele unerläßlichen Befugnissen. Pinay verwahrte sich gegen den Terminus „Vorbedingung“, sprach statt dessen von „Sachgebiete[n], deren Studium von der französischen Delegation gewünscht werde“. Hallstein pflichtete dieser Auslegung bei und bedauerte zugleich, sich der Bemerkung Spaaks über die institutionelle Ausgestaltung nicht anschließen zu können. Nach zähen Verhandlungen, die erst gegen vier Uhr am Morgen des 3. 6. abgeschlossen wurden, konnte schließlich doch noch ein für alle Delegationen tragfähiger Kompromiß erzielt werden ${ }^{119}$.

In der Resolution von Messina sprachen sich die Delegationen für die Weiterentwicklung gemeinsamer Institutionen, den Zusammenschluß der nationalen Volkswirtschaften, die Errichtung eines Gemeinsamen Marktes und die Harmonisierung der Sozialpolitik aus. Neben dem Maßnahmenkatalog für die sektorale Integration im Bereich des Transportwesens, der Energie und der Schaffung einer gemeinsamen Organisation zur friedlichen Nutzung der Atomkraft stand die Durchführung des Gemeinsamen Marktes im Mittelpunkt der Entschließung. Im Sinne Frankreichs sah sie zunächst die Prüfung bestimmter Fragen vor. Dazu gehörten im einzelnen das Verfahren des Zollabbaus im Innern der Gemeinschaft und die Vereinheitlichung der Zölle gegenüber Drittländern, die Harmonisierung der Politik auf wirtschaftlichem, sozialem und finanziellem Gebiet, die Annahme von Methoden zur Koordinierung der Währungspolitik, die Schaffung eines Anpassungs- und Investitionsfonds, die Freizügigkeit der Arbeitskräfte oder die Sicherung des freien Wettbewerbs. Die Minister vereinbarten die Einberufung mehrerer Konferenzen, die von einem Komitee von Regierungsdelegierten und Sachverständigen unter dem Vorsitz einer noch nicht benannten politischen Persönlichkeit vorzubereiten waren. Ein Gesamtbericht sollte den Außenministern am 1. 10. vorliegen ${ }^{120}$.

In Bonn fielen die Reaktionen auf die Messina-Konferenz nicht gerade überschwenglich aus. Die SPD-Opposition begrüßte die Ergebnisse und brachte mit dem ausdrücklichen Bekenntnis zur Fortsetzung der Integration im Rahmen der Montanunion eindrucksvoll zum Ausdruck, daß sie sich von der Europapolitik der letzten Jahre mehr und mehr entfernte ${ }^{121}$. Die Bundesregierung war mit dem Ergebnis der Konferenz, das durch das „Zurückgehen auf [eine] Minimallinie [...] hinter [den] bescheidenen Erwartungen“ zurück blieb, hingegen nicht zufrieden ${ }^{122}$. Wenn Hallstein in einem Runderlaß an die deutschen Missionen „Ermüdungserscheinungen“ dafür verantwortlich machte, daß die Resolution, „dem Geist der Konferenz nicht voll [entsprechend]“, in manchen Punkten „unnötig schwach formuliert" worden sei ${ }^{123}$, so stellt er den Verlauf der Konferenz sicher-

119 Ebd., Konferenz der EGKS-Außenminister vom 1./2. 6. 1955, MAE 11/55, 13. 6. 1955, Entwurf.

${ }^{120}$ S. Resolution der Messina-Konferenz, 3. 6. 1955, in: Bulletin 1955, S. 1690 f,; Küsters, Gründung, S. $122-124$.

121 Vgl. Paterson, SPD, S. $122 \mathrm{f}$.

122 PA, BStS, Bd. 350, Hallstein an AA, Tel., 3. 6. 1955, Verschlüsselt; s.a. Küsters, Walter Hallstein, S. 91.

123 PA, Abt. 2, Bd. 902, Bl. 92-95, Hallstein an Ankara etc., 225-00/7961/55, 6. 7. 1955. 
lich in ein zu günstiges Licht. Schenkt man den Erinnerungen Adenauers Glauben, befürchtete er nun, der eingeschlagene Weg zur wirtschaftlichen Integration könne das eigentliche Ziel, die politische Union, verfehlen ${ }^{124}$. Tatsächlich sorgte sich der Staatssekretär eher darum, für das wenig berauschende Resultat verantwortlich gemacht zu werden. Schon die Tatsache, daß nicht der Kanzler, sondern nur sein Adept in Sizilien erschienen war, hatte nämlich bei den Außenministern Enttäuschung hervorgerufen ${ }^{125}$. Die Verhandlungsführung Hallsteins entfachte dann vor dem Hintergrund der soeben gewonnenen Souveränität und der stagnierenden Wiedervereinigungsdiskussion bei den Partnern „ein gewisses Mißtrauen“, die Deutschen könnten die Europapolitik vernachlässigen und sich nach Osten wenden ${ }^{126}$. Selbst in Übersee machten die Politiker keinen Hehl aus der Sorge, die Bundesrepublik könne in ihren Anstrengungen um die europäische Integration erlahmen. Die Europäer, so diktierte Dulles etwa Erhard am 7. 6. ins Stammbuch, hätten die Pflicht, sich zu vereinigen, um nicht erneut die amerikanische Hilfe anrufen zu müssen ${ }^{127}$. Der Kanzler legte daher bei seiner Reise nach Washington eine Woche später großen Wert darauf, dem amerikanischen Außenminister klarzumachen, daß die retardierenden Elemente nicht in Bonn, sondern in Paris säßen. Hallsteins Auftrag sei es gewesen, die europäische Integration voranzutreiben. Pinay aber habe aus Rücksicht auf die innenpolitische Lage und die bevorstehenden Parlamentswahlen Widerstand geleistet. Gegenwärtig, so lautete das Fazit Adenauers, sei die Schaffung supranationaler Organisationen nicht möglich ${ }^{128}$.

In Paris fielen die Reaktionen mit genau umgekehrten Vorzeichen aus. Die Regierung zeigte sich zufrieden, die Opposition äußerte sich entsetzt. Pinay betrachtete den wenig sensationellen Ausgang des Ministertreffens als „un effort réel et fructueux [...] pour dégager les bases concrètes de la construction européenne“. Mit Stolz vermerkte er, daß die Resolution von Messina in den Passagen über die Erreichung der angestrebten Ziele den französischen Forderungen nach einem schrittweisen Vorgehen entsprach ${ }^{129}$. Um den Unmut der Deutschen nicht anzustacheln, ließ er in Bonn versichern, man werde im Sachverständigenausschuß konstruktiv mitarbeiten und mit qualifizierten und europafreundlichen Personen vertreten sein, um den europapolitischen „Wagen im Rollen zu halten“130.

In scharfem Gegensatz dazu verunglimpften die antieuropäischen Kritiker an der Seine diesen bescheidenen Neubeginn als "Fausse relance". Vor dem Hinter-

${ }^{124}$ S. Adenauer, Erinnerungen, S. 1955-1959, S. 30.

$125 \mathrm{Vgl}$. Rimbaud, Pinay, S. 304. Adenauer entschuldigte sein Fehlen gegenüber dem italienischen Ministerpräsidenten mit wichtigen innenpolitischen Aufgaben, vor allem der Vorbereitung der Wehrgesetze (Adenauer an Scelba, 27. 5. 1955, in: Adenauer, Briefe 1953-1955, S. 293 f.).

126 PA, Abt. 2, Bd. 901, Bl. 145-147, Erklärung von Ophüls in der Ressortbesprechung im AA vom 20. 6. 1955; s.a. Garnier an Pinay, Tel. 290/94, 4. 6. 1955, Réservé, in: DDF 1955, Bd. 1, S. 731 f.; Artikel Kornickers, in: „Schwäbische Landeszeitung/Augsburger Zeitung“, 7.6. 1955, im Auszug auch in: BDFD III, S. 421-423.

127 S. Unterredung zwischen Dulles und Erhard vom 7.6. 1955, Limited Official Use, im Auszug in: FRUS 1955-1957, Bd. 4, S. $291 \mathrm{f}$.

128 S. Unterredung zwischen dems. und Adenauer vom 13.6. 1955, im Auszug in: ebd., S. 297.

129 Pinay an diplomatische Vertreter, Zirkulartel. 49, 10. 6. 1955, in: DDF 1955, Bd. 1, S. 756-758, hier S. 757; s.a. Dillon an Dep. of State, Tel. 5420, 10.6. 1955, Secret, in: FRUS 1955-1957, Bd.4, S. 293-295; Küsters, Gründung, S. 126.

130 PA, Ref. 200, AZ 85.11/0, Bd. 1, von Maltzan an AA, FS Nr. 359, 15. 6. 1955, Verschlüsselt. 
grund der nahenden Ost-West-Gipfelkonferenz in Genf sahen sie darin nur einen neuen Schritt zur Vertiefung der europäischen Teilung und gegen die Verstärkung der Entspannungspolitik in Gesamteuropa. "Ceux qui ont poussé à la réunion de la Conférence de Messine sont ceux qui souhaitent l'échec de la Conférence à Quatre [...]; l'amélioration encore fragile mais très réelle de la situation internationale diminue les chances de succès des entreprises des boutefeux obsédés par l'idée de maintenir à tout prix et à des fins d'agression l'Allemagne Occidentale dans l'alliance atlantique" ${ }^{131}$. Derartige Polemiken waren indes im großen und ganzen die Ausnahme. Die „relance européenne“ erregte in der französischen Öffentlichkeit nicht annähernd jene Emotionen wie die EVG. In den Parteien nahmen sich vornehmlich die Spezialisten der Materie an, und in der Presse überwogen informative Artikel132. Allerdings zeigte die Diskussion doch eines immer wieder: Als eingefleischte Individualisten standen die Franzosen der Integration nicht nur per se argwöhnisch gegenüber; sie mißtrauten auch der Integrationsbereitschaft der Deutschen und verdächtigten sie des Strebens nach einem deutsch geprägten Europa $^{133}$.

\section{Schwierige Beratungen in Brüssel}

Mitte Juni verständigten sich die Sechs auf diplomatischem Wege darauf, Spaak mit dem Vorsitz des in Messina beschlossenen Sachverständigenkomitees zu beauftragen ${ }^{134}$. Nachdem der belgische Außenminister die Leiter der Delegationen zu einer Vorbesprechung des Sachverständigenausschusses zum 1. 7. nach Brüssel eingeladen hatte, waren die Regierungszentralen gefordert, ihre Marschrouten festzusetzen. Im Auswärtigen Amt wirkte der in Messina zum Ausdruck gebrachte Argwohn der Partnerstaaten gegenüber Deutschland noch nach, der sich nach der Moskauer Einladung an Bonn zur Aufnahme diplomatischer Beziehungen vom 7.6.135 noch verstärkte. Als zuständiger Unterabteilungsleiter war Ophüls fest entschlossen, die Befürchtungen zu zerstreuen, „da eine Änderung der deutschen Politik mit Bezug auf die europäische Integration nicht vorliege noch beabsichtigt sei [sic!]“. Für die Arbeit des Spaak-Komitees, wie es bald genannt wurde, erwartete er angesichts der knapp bemessenen Zeit bis zur geplanten Außenministerkonferenz im Oktober nicht in allen Diskussionsfeldern große Ergebnisse ${ }^{136}$. Ende Juni verständigten sich das Auswärtige Amt und das Bundeswirtschaftsministerium auf der Basis einer von Müller-Armack und von der Groeben entwickelten vermittelnden Position, die die Vorteile des Freihandels innerhalb eines großen Wirtschaftsraums verwirklichen wollte, auf einen Kompromiß: Die funktionale wirtschaftliche Integration sollte in drei Phasen durch eine Zoll-

131 AMAE, DE-CE, Bd. 611, Bl. 243-249, „Fausse relance“, o.D. Dem Inhalt der zwischen dem 15.6. und dem 18. 7. verfaßten Schrift kann entnommen werden, daß der Autor aus dem linken, möglicherweise kommunistischen Lager stammte.

132 Vgl. Bjøl, La France, S. 273-294.

133 Vgl. „Die Zeit“, 1. 12. 1955.

134 S. Rivière an Pinay, Tel. 362, 13.6. 1955, Urgent, in: DDF 1955, Bd. 1, S. 768 f.; Spaak, Memoiren, S. 305; Küsters, Gründung, S. $124 \mathrm{f}$.

$135 \mathrm{Vgl.} \mathrm{Kap.} \mathrm{IV.1.1.}$

$136 \mathrm{PA}, \mathrm{Abt} .2$, Bd. 901, Bl. 145-147, Erklärung von Ophüls in der Ressortbesprechung im AA vom 20.6. 1955 . 
union mit einem Institutionengefüge ergänzt werden und in einen Gemeinsamen Markt einmünden. Für die erste Etappe wurde die Konvertibilität der Währungen vorgesehen, für die zweite die Erarbeitung der funktionalen Merkmale des Gemeinsamen Marktes durch ein Gremium der beteiligten Staaten, für die dritte schließlich die institutionelle Sicherung des Gemeinsamen Marktes. Ophüls plädierte dafür, zunächst eine positive Grundentscheidung der Sechs für den Gemeinsamen Markt zu erreichen, wobei er in den Details wie bei der institutionellen Ausgestaltung einen mittleren Kurs zu steuern beabsichtigte, der das vorhandene Mißtrauen der Partner nicht schüren durfte ${ }^{137}$.

Die weiteren Diskussionen zwischen den Bonner Ressorts über den Zielkatalog für die Brüsseler Beratungen ließen die vor der Messina-Konferenz notdürftig überbrückten Differenzen indes erneut aufbrechen. Die Schuman-Plan-Abteilung im Bundeswirtschaftsministerium unter von der Groeben wollte den Gemeinsamen Markt über die freie Konvertibilität der Währungen, die Beseitigung der Beschränkungen des Waren-, Dienstleistungs- und Kapitalverkehrs und Erleichterungen im Wirtschaftsverkehr erreichen. Erhard setzte aber durch, daß in der Position seines Ministeriums die Schaffung einer Zollunion als Verhandlungsziel zugunsten eines weltweiten Freihandels gestrichen und nur als eine vorrangige Option anerkannt wurde ${ }^{138}$. Er lehnte also, was die Zollunion vorsah, den gemeinsamen Außentarif ab und sprach sich statt dessen im Sinne des Freihandels dafür aus, Zölle und andere Handelsbeschränkungen nur für Waren aus dem Gebiet der Freihandelszone zu beseitigen, die einzelnen Zolltarife gegenüber Drittländern aber zu erhalten. Auch die in der Zollunion notwendige enge Koordinierung der Wirtschaftspolitik entfiel damit ${ }^{139}$.

Im Auswärtigen Amt, wo die Amtsübernahme von Brentanos und der Wechsel von Blankenhorn zur NATO nach Paris den Supranationalisten nun „freie Bahn" 140 verschaffte, befürchtete man, die Zweifel gegenüber der deutschen Europapolitik mit diesem Ansatz eher noch anzustacheln. In einem Runderlaß an die deutschen Botschaften gab Hallstein am 6. 7. Order, bei sich bietender Gelegenheit Klarheit darüber herbeizuführen, „daß die Politik der Bundesregierung mit Bezug auf die europäische Integration nicht nur unverändert ist, sondern in einer Wiederaufnahme der Integration mit allen Folgen, die sich daraus ergeben, ein wesentliches Ziel der nächsten Jahre ansieht“141. Von Brentano, den Adenauer zur Wachsamkeit gegenüber Erhards Europapolitik aufgefordert und zur Fortsetzung der europäischen Integration als „eine der wesentlichsten Richtlinien unserer Politik“ verpflichtet hatte ${ }^{142}$, betonte am selben Tag vor der Beratenden Versammlung des Europarates dezidiert die Kontinuität der Bonner Integrationspolitik ${ }^{143}$.

137 S. Ressortbesprechung im AA vom 25.6. 1955, in: BDFD I, S. 589-592.

138 Vgl. Küsters, Gründung, S. 141-143.

139 Zur Unterscheidung zwischen Zollunion und Freihandelszone vgl. Küsters, Gründung, S. 165.

140 Schwarz, Adenauer, Bd. 2, S. 195. Zu den Vorbehalten Blankenhorns gegenüber dem Gemeinsamen Markt und EURATOM s. Blankenhorn, Verständnis, S. 246, Tb. 3. 2. 1956.

141 PA, Abt. 2, Bd. 902, Bl. 92-95, Hallstein an Ankara etc., 225-00/7961/55, 6. 7. 1955.

142 Adenauer an von Brentano, 27.6. 1955, in: Adenauer, Briefe 1953-1955, S. 304; s.a. Küsters, Walter Hallstein, S. 93.

${ }^{143}$ S. Rede von Brentanos vor der Beratenden Versammlung des Europarates, 6. 7. 1955, in: von Brentano, Welt, S. 134-136. 
Gegenüber Monnet sprach er sich für die Erweiterung der Montangemeinschaft wie für die Verwirklichung der Messina-Resolution „im Sinne der Souveränitätsabtretung und nicht der Kooperation" aus ${ }^{144}$.

Die Umsetzung dieser Richtlinie fiel dem Amt indes keineswegs leicht. Ophüls hielt echte Fortschritte bei der Gesamtintegration angesichts der französischen Bedenken für unwahrscheinlich. Nur auf dem Atomsektor versprach er sich Erfolg. Da er außerdem von einer wirtschaftlichen Integration keine politischen Einigungsschritte erwartete, riet er dazu, kurzfristige ökonomische Ambitionen den politischen Interessen unterzuordnen. Als die Leitlinien für die deutsche Delegation am 7. 7. im Wirtschaftskabinett unter der Leitung von Blücher festgesetzt wurden, vermochte sich das Auswärtige Amt aber nicht vollständig zu behaupten. Zwar konnte die generelle Ablehnung supranationaler Institutionen verhindert werden. Das Wirtschaftsministerium setzte sich aber mit der Auffassung durch, daß das Konzept der additiven Teilintegration ausdrücklich nur bei der Atomenergie erlaubt sei145. Adenauer erließ daraufhin eine „Richtlinie zur Fortführung der Integration“, die sich für den „Primat der politischen Zweckmäßigkeit“ aussprach $^{\mathbf{1 4 6}}$ und damit sowohl die Kritikaster in Bonn als auch in Paris ins Visier nahm. Die Bundesrepublik, so unterstrich er dieser Tage im Kabinett, müsse als „Vorkämpferin des europäischen Gedankens" auftreten ${ }^{147}$. Er tat gut daran, die Erwartungen nicht zu hoch zu schrauben.

Frankreich strebte ein europäisches Organ für das Transportwesen mit präzisen, aber beschränkten Befugnissen und angesichts knapper Energieressourcen in Europa eine gemeinsame Politik für die Entwicklung und optimale Nutzung der herkömmlichen Energie an. Besonderes Gewicht legte man aus psychologischen wie gesamtpolitischen Erwägungen auf die gemeinsame Atomorganisation. Das von den Wahrern der nationalen Atomsouveränität ausgegebene Argument, Frankreich könne in einer solchen Zusammenarbeit angesichts seines Entwicklungsvorsprungs im Nuklearbereich nichts gewinnen, galt aus Sicht ihrer Gegner als wenig stichhaltig. „En quelques années“, so meinte Etienne Hirsch, mittlerweile Commissaire général au Plan, „avec la disparition rapide du secret et la collaboration offerte par les Etats-Unis et la Grande-Bretagne, nous serons rattrapés par l'Allemagne. “148

Hinsichtlich des Gemeinsamen Marktes sahen die französischen Vorstellungen wesentlich restriktiver aus, wie aus einer Aufzeichnung von Bernard Clappier, dem Direktor für auswärtige Wirtschaftsbeziehungen im Finanz- und Wirtschaftsministerium, hervorgeht. Die Ursachen lagen auf der Hand. Hinsichtlich der Kontingentierung hatten die Partner ihren Handel in den vergangenen Jahren weit stärker liberalisiert als Frankreich. In den Bereichen Agrarprodukte, Rohstoffe und Fertigwaren lag man mit 50\%, 90\% und 51\% jeweils weit hinter den

144 PA, Abg.-Liste Ministerbüro, Bd. 48, Unterredung zwischen dems. und Monnet vom 4. 7. 1955, 5. 7. 1955.

145 S. BA, B 136, Bd. 1310, Unterredung bei Blücher vom 7. 7. 1955; Küsters, Gründung, S. 144.

146 PA, Ref. 200, AZ 85.11/0, Bd. 1, Erklärung von Ophüls in der Ressortbesprechung im AA vom 11. 7. 1955.

147 Kabinettssitzung, 6. 7. 1955, in: Kabinettsprotokolle, Bd. 8, S. 406.

148 AMAE, PA-AP, Papiers Schuman, Bd. 2, Bl. 155-160, Hirsch an „Le Ministre“, 21. 6. 1955, nebst Aufzeichnung. 
Vergleichszahlen der Sechsergemeinschaft. Darüber hinaus gehörte Frankreich mit der Bundesrepublik und Italien zu den Hochzolländern mit durchschnittlich $20 \%$ bis $30 \%$, während die BENELUX-Staaten an ihren Grenzen lediglich 5\% bis 10\% Zoll erhoben. Im Gegensatz zu einigen Wirtschaftskreisen zog Clappier aus diesem Vergleich aber nicht die Folgerung, Fortschritte auf dem Weg zum Gemeinsamen Markt von einer vorherigen Harmonisierung der Finanz-, Wirtschafts- und Sozialpolitik abhängig zu machen. Denn damit würde der erste Schritt unweigerlich hinausgezögert und geriete auch in einen Gegensatz zur Entwicklung der Wirtschaftsunion im BENELUX-Raum. Clappier plädierte vielmehr für eine nach Kontingenten bzw. Zöllen differenzierte, fortschreitende Gründung des Gemeinsamen Marktes mit einem gemeinsamen Investitionsfonds. Die Abschaffung der Kontingentierung konnte er sich zumindest für Industrieprodukte relativ rasch vorstellen, wenn die Agrarprodukte ausgeklammert und Begleitmaßnahmen getroffen würden. Schwieriger erschien ihm das Problem der Zölle, und er bestand darauf, daß der nur etappenweise eingeführte gemeinsame Außenzoll der Gemeinschaft relativ hoch sein müsse ${ }^{149}$.

Unter Einbeziehung dieser beiden Stellungnahmen faßte ein interministerielles Komitee Anfang Juli recht allgemein gehaltene Instruktionen für die französische Delegation ab, die unter der Leitung von Felix Gaillard stand. Im Zentrum des französischen Interesses standen rasche Ergebnisse bei der Schaffung einer europäischen Atomorganisation mit gemeinsamem Etat zur Finanzierung von Installationen und Forschungen im Bereich der angewandten, nicht militärischen Nuklearforschung. Die Bildung einer supranationalen Organisation mit Monopolstellung wurde à la longue nicht ausgeschlossen, wobei die nationalen Nuklearprogramme aber in der Verantwortung der Regierungen bleiben sollten, obwohl dies mit der Resolution von Messina kaum im Einklang stand ${ }^{150}$. Im Sinne Hirschs befürwortete die Order auch ein europäisches Organ für das Transportwesen sowie eine bessere Koordinierung der Investitionen im Bereich der herkömmlichen Energie. Mit Blick auf den Gemeinsamen Markt wies sie der Brüsseler Tagung die Aufgabe zu, gewisse Fragen zu prüfen, „dont la solution préalable commande la réalisation du Marché commun". Mit Blick auf die öffentliche Meinung galt insbesondere die Harmonisierung der Soziallasten als unabdingbar ${ }^{151}$. Besonders heikel wirkten aber auch die Akzeptierung eines internationalen Vertrags über die sukzessive Abschaffung der Zölle und Kontingente, die Administrierung der Ausschlußklauseln durch eine supranationale Behörde, das Anzeigen des Willens zu einer Zollunion beim GATT, die Begleitung der Abschaffung der Kontingente in einer Vorlaufphase durch eine Kompensationssteuer. Eine definitive Entscheidung bezüglich der ersten beiden Komplexe sah die Instruktion erst nach einer Regelung über den Investitionsfonds und den Außenzolltarif vor. Hinsichtlich der letzten beiden Fragen wollte sich Frankreich erst dann äußern, wenn die Part-

${ }^{149}$ Ebd., Bl. 165-168, Aufzeichnung Clappier, o.D. Hirsch schickte diese Aufzeichnung neben seiner eigenen am 21.6. 1955 an "Le Ministre", bei dem es sich wohl um Wirtschaftsminister Pflimlin oder Justizminister Schuman handelt.

150 S. ebd., Bl. 171 f., Aufzeichnung, mit handschriftlicher Marginalie „Pflimlin 27/7“.

151 Instruktionen für die französische Delegation zur Brüsseler Vorkonferenz, Juli 1955, Confidentiel, in: BDFD I, S. 592-596, hier S. 595. 
ner klare Vorstellungen über die Realisierung des Gemeinsamen Marktes äußerten $^{152}$.

Angesichts derart fundamentaler Meinungsverschiedenheiten in den Grundkonzeptionen der beteiligten Regierungen standen die Diskussionen des zur Umsetzung der Messina-Resolution seit Anfang Juli tagenden Sachverständigenausschusses unter keinem günstigen Stern ${ }^{153}$. Als vorteilhaft erwies sich die Tatsache, daß die allgemein als gering eingestuften Erfolgsaussichten und die Genfer Konferenzen das öffentliche Interesse an den Beratungen rasch erlahmen ließen ${ }^{154}$. Neben den sechs EGKS-Staaten nahm nach einmonatigem Zögern auch England als Beobachter an den Beratungen teil, ohne sich aber mit den Zielen der MessinaResolution identifizieren zu wollen ${ }^{155}$. Die britische Mitwirkung wurde von Frankreich lebhaft befürwortet ${ }^{156}$, intern aber mit der Forderung versehen, daß das Ziel der Vergemeinschaftung bestimmter europäischer Ressourcen nicht durch die englische Teilnahme in Frage gestellt werden dürfe ${ }^{157}$.

Als Chef der deutschen Vertreter nutzte Hallstein die konstituierende Sitzung der Delegationsleiter am 9. 7., um abermals die Zweifel an der deutschen Europapolitik zu zerstreuen - mit Erfolg. Seine mit Spannung erwartete Rede legte ein überzeugendes Bekenntnis für die Gesamtintegration ab und sprach sich im Sinne der Richtlinie Adenauers mit Ausnahme der Atomenergie gegen das Konzept der additiven Teilintegration aus ${ }^{158}$. Mit dieser Klarstellung ging es dem Staatssekretär gewiß nicht nur um die Außenwirkung, sie diente auch als Richtlinie für die Delegation und die Ministerien am Rhein, zielte also vor allem auch in Richtung Erhard ${ }^{159}$. Zehn Tage später, am 18. bzw. 20. 7., begann die Arbeit der Ausschüsse und Unterausschüsse, die vom Lenkungsausschuß der Delegationsleiter unter dem Vorsitz von Spaak dirigiert und koordiniert wurde ${ }^{160}$. Der Optimismus einiger Beamter wich sehr bald der Ernüchterung. Nach wochenlangen Diskussionen war man über die Erörterung von Grundsatzfragen nicht hinausgekommen ${ }^{161}$.

152 S. Comité interministériel vom 5. 7. 1955, in: DDF 1955, Bd. 2, S. 19-23.

153 Zur Arbeit des Spaak-Komitees vgl. von der Groeben, Deutschland, S. 275-279; Müller-Armack, Weg, S. 104-110; Spaak, Memoiren, S. 317-319; Dumoulin, Travaux; Küsters, Gründung, S. 145205.

154 Vgl. ebd., S. 135; zur Genfer Gipfel- bzw. Außenministerkonferenz s. Kap. IV.1.1.

${ }_{155}$ Zur englischen Haltung gegenüber der Messina-Resolution vgl. umfassend: Kaiser, Großbritannien, S. 29-67; Küsters, Gründung, S. 135-141.

156 S. Pinay an Rivière, Tel. 1002/05, 1.7. 1955, Extrême urgence, Priorité absolue, in: DDF 1955, Bd. 2, S. 2 f.

157 S. Instruktionen für die französische Delegation zur Brüsseler Vorkonferenz, Juli 1955, Confidentiel, in: BDFD I, S. 596; Comité interministériel vom 5. 7. 1955, in: DDF 1955, Bd. 2, S. 22 f.

158 S. Rede Hallsteins auf der Sitzung der Delegationsleiter, 9. 7. 1955, in: Bulletin 1955, S. 1063 f.; zur Reaktion der Kollegen s. Rivière an Pinay, Tel. 452/58, 9. 7. 1955, Urgent, in: DDF 1955, Bd. 2, S. $40 f$.

159 S. PA, Ref. 200, AZ 85.11/0, Bd. 1, Erklärung von Ophüls in der Ressortbesprechung im AA vom 11. 7. 1955.

160 S. Rivière an Pinay, Tel. 473, 20. 7. 1955, in: DDF 1955, Bd. 2, S. 112-115; zur Organisation und personellen Ausstattung der Brüsseler Konferenz vgl. Küsters, Gründung, S. 146-156.

$161 \mathrm{Zu}$ den Beratungen bis Anfang September 1955 s. AMAE, DE-CE, Bd. 612, Bl. 53-56, Mission des Generalsekretärs der Brüsseler Konferenz Calmes an die Delegationsleiter, Informationsbericht Nr. 3, 2. 8. 1955, Confidentiel; ebd, Bl. 74-76, dies. an dies., Informationsbericht Nr. 4, 10.8. 1955, Confidentiel; PA, Ref. 200, AZ 85.11/0, Bd. 1, von Stempel an Ophüls, Aufzeichnung 210 225-00/9231/55, 9. 8. 1955; ebd., Abt. 2, Bd. 899, B1. 159-189, Bericht des AA und BMWi über den Stand der Verhandlungen der Brüsseler Konferenz, 27. 10. 1955; Dufournier an Pinay, 
Die von Ophüls in Vertretung Hallsteins geführte Bonner Delegation zeigte wenig Interesse an der von Paris gewünschten Atomgemeinschaft, während die französischen Vertreter mit Gaillard an der Spitze dem Projekt des Gemeinsamen Marktes distanziert gegenüberstanden. In der Frage der Nuklearenergie befürworteten die Deutschen eine supranationale Behörde mit weitreichenden Befugnissen für Forschung und Entwicklung, während die Franzosen eine Atomagentur ohne Monopolstellung, ohne föderale Struktur oder bindende Beschlüsse, aber mit gemeinsamem Budget, freiem Zugang zu den Ressourcen und gemeinsamen Investitionen in zentralen Bereichen wünschten. Da Belgien offenbar nicht bereit war, Frankreich sein Uranerz aus Belgisch-Kongo zum selben Preis zu liefern wie den USA, sahen die Franzosen im Projekt der europäischen Atomgemeinschaft nicht zuletzt eine Möglichkeit, das amerikanische Monopol zur Herstellung angereicherten Urans zu brechen. Eine der Hauptaufgaben der neuen Gemeinschaft sollte denn auch ihrer Meinung nach der Bau einer Isotopentrennanlage sein ${ }^{162}$.

Hinsichtlich des Gemeinsamen Marktes ging es vor allem um die Frage der einzelnen Aufbauschritte. Die deutschen Sachverständigen sprachen sich für die Beseitigung der Beschränkungen im Waren- und Kapitalverkehr aus, für den Abbau der Zölle und mengenmäßigen Beschränkungen sowie für Maßnahmen zur Stabilisierung des Gemeinsamen Marktes durch Schutzklauseln und Übergangsregelungen. Außerdem plädierten sie für die Prüfung eines institutionellen Systems. Ihre französischen Kollegen hingegen wollten diese Untersuchungen mit den Ergebnissen der Unterausschüsse für Sozialfragen und Investitionen verknüpfen. Jegliche Liberalisierung auf dem Handelssektor gedachten sie mithin nur zuzulassen, wenn Beihilfen durch einen Fonds gesichert und die sozialen Belastungen ausgeglichen würden, um die Konkurrenzfähigkeit der französischen Produzenten zu gewährleisten. Im Fall der Einigung über diese Bereiche waren sie bereit, die noch bestehenden Kontingente für den französischen Markt fallenzulassen. Bedenken äußerte die französische Delegation hinsichtlich der Schaffung einer Zollunion. Neben den Differenzen über die Frage des Zeitpunktes des Gemeinsamen Marktes führte vor allem die Diskussion über den Termin des Abbaus der Zollschranken und des Aufbaus gemeinsamer Außentarife zu erheblichen Meinungsverschiedenheiten. Frankreich vermied es, sich auf ein definitives Datum festzulegen, während die übrigen Staaten in der Festsetzung des Termins eine unabdingbare Voraussetzung für den Beginn eines wirklichen Gemeinsamen Marktes sahen. Hinsichtlich des Außentarifs verlangten die Niedrigzolländer, die Zölle möglichst tief zu halten, wohingegen Frankreich demgegenüber einen möglichst hohen Zollschutz bevorzugte. Auch beim Abbau der mengenmäßigen Beschränkungen im Innern und an den Außengrenzen der künftigen Zollgemeinschaft konnten die Experten keine einmütige Regelung finden. Die französischen wollten den Abbau der noch bestehenden Kontingente der OEEC überlassen, die deutschen und niederländischen befürworteten hingegen ein von den Sechs ausge-

Tel. 531/33, 31. 8. 1955, Urgent, in: DDF 1955, Bd. 2, S. 383; vgl. Küsters, Gründung, S. 161-202; Weilemann, Anfänge, S. 31-47.

162 Vgl. Eckert, Kernenergie, S. 319; Guillen, La France et la négociation du traité d'Euratom, S. 396398 u. 404-407; Weilemann, Anfänge, S. $37 \mathrm{f}$. 
arbeitetes System, um möglichst schnell zu Erfolgen zu gelangen. Differenzen zwischen Deutschen und Franzosen ergaben sich darüber hinaus aus der Frage der zu erwartenden Belastungen durch den Zoll- und Kontingentabbau. Frankreich sah den Hauptgrund für Verzerrungen der Wettbewerbslage in den unterschiedlichen Sozialbestimmungen der Partnerstaaten und forderte daher eine Reihe sozialpolitischer Harmonisierungsmaßnahmen. Hart umstritten waren schließlich die Modalitäten der Inanspruchnahme der vorgesehenen Investitionsund Anpassungsfonds. Nach den Vorstellungen der Franzosen und Italiener sollte letzterer auch Leistungen an Unternehmen vorsehen, was die Deutschen ebenso ablehnten wie die französische Forderung nach Einbeziehung der Landwirtschaft.

Angesichts dieser mannigfachen, mitunter fundamentalen Differenzen konnte Spaak seinen Kollegen auf der Außenministerkonferenz von Nordwijk am 6.9. nur einen bescheidenen Zustandsbericht über die bisherigen Arbeiten und die sachlichen Gegensätze vorlegen ${ }^{163}$. Hallstein sah sich erneut veranlaßt, Mißverständnisse in bezug auf die Haltung der Bundesregierung zur Frage der europäischen Integration auszuräumen. Wenn auch die Methoden zur Schaffung eines geeinten Europa in der Bundesrepublik diskutiert würden, versuchte er seine Kollegen zu beruhigen, stünde das Ziel als solches doch keineswegs in Frage. Der Kanzler wünsche „rasche europäische Ergebnisse“, denn ein geeintes Europa sei eine Garantie des Friedens und notwendig, um die ihm zufallende Rolle bei der globalen Entspannung zu übernehmen ${ }^{164}$. Seine ursprünglich getroffene Wortwahl, Adenauer hoffe, „kurzfristig zu wesentlichen Ergebnissen zu gelangen“, hielt der Staatssekretär mit dem Abstand einiger Wochen für so unglücklich, daß sie auf Bitten des Auswärtigen Amtes aus dem Protokoll gestrichen wurde ${ }^{165}$. Freilich änderte dies nichts an der Grundtatsache, daß Adenauer gegen den fortgesetzten Widerstand Erhards ${ }^{166}$ vor dem Hintergrund der Bewegung in der deutschen Ostpolitik im Zuge seiner Moskaureise eine Forcierung der europäischen Integration für notwendig hielt ${ }^{167}$.

Pinays Ansprache in Nordwijk stand ganz im Zeichen eines vor der Konferenz im Quai d'Orsay erfolgten Überdenkens der bisherigen restriktiven Position. Die Unterabteilung Wirtschaftliche Kooperation hatte eine Präzisierung der bisherigen Instruktionen für die Brüsseler Delegation gefordert und davor gewarnt, in bezug auf den Gemeinsamen Markt die negative oder dilatorische Haltung aufrechtzuerhalten, weil man damit den Fortschritt der Diskussionen blockiere ${ }^{168}$. Eine definitive Position zum Gemeinsamen Markt schien aber noch verfrüht, da die Arbeiten in Brüssel noch nicht weit genug gediehen waren. Der Festsetzung eines Termins für den Eintritt in den Markt mochte man nicht zustimmen, weil

163 S. PA, Abt. 2, Bd. 903, Bl. 130-153, Konferenz der EGKS-Außenminister vom 6. 9. 1955, MAE 322d/55, 28. 9. 1955, Entwurf; Küsters, Gründung, S. 157 f.

164 PA, Abt. 2, Bd. 903, Bl. 156-159, Rede Hallsteins auf der Konferenz der EGKS-Außenminister vom 6.9. 1955.

165 Ebd., B1. 130-153, Konferenz der EGKS-Außenminister vom 6. 9. 1955, MAE 322d/55, 28. 9. 1955, Entwurf; ebd., Bl. 111 f., Änderungsvorschlag der deutschen Delegation MAE 33d/56, 8. 2. 1956.

166 S. Artikel Erhards, in: „Deutsche Korrespondenz“, 21. 7. 1955, auch in: Erhard, Gedanken, S. 442445.

167 Vgl. Kap. IV.1.1; Küsters, Gründung, S. 160

168 S. AMAE, DE-CE, Bd. 612, B1. 90-95, Aufzeichnung der Unterabt. für wirtschaftliche Kooperation im MAE, 1. 9. 1955. 
damit nur Illusionen, aber auch Befürchtungen geweckt würden. Da das Problem offensichtlich psychologischer Natur war, verfielen die Beamten auf den Ausweg, „de créer l'impression qu'on s'engage dans la voie du marché commun“. Den „effet psychologique" glaubte man dadurch zu erzielen, daß man der Festsetzung eines Termins für die erste Etappe zum Gemeinsamen Markt zustimmen wollte, sofern Maßnahmen zur sozialen Harmonisierung wie Angleichung der Wochenarbeitslöhne, Vergütung der Überstunden und Gleichheit der Löhne für Männer und Frauen getroffen würden ${ }^{169}$.

Ohne auf die Frage des Datums einzugehen, unterstrich Pinay in diesem Sinne den Willen Frankreichs, an der Resolution von Messina festzuhalten. Da er aber den Eindruck gewonnen hatte, daß die BENELUX-Staaten sich zunehmend stärker auf den Gemeinsamen Markt konzentrierten und Fortschritte bei der sektoralen Integration von solchen bei der horizontalen abhängig zu machen wünschten ${ }^{170}$, brachte er zugleich den Wunsch zum Ausdruck, das Arbeitstempo der Brüsseler Sachverständigen nicht von den Diskussionen über den Gemeinsamen Markt abhängig zu machen. Nach einer Eingabe Spaaks betonte er, daß die verschiedenen Maßnahmen zur Errichtung des Gemeinsamen Marktes "gleichzeitig“ getroffen werden müßten, die Harmonisierung der Wirtschafts-, Finanz- und Sozialpolitik also nicht vorher durchzuführen sei. Am Ende ging man auseinander, ohne Entscheidungen über die weitere Verhandlungslinie der Brüsseler Konferenz getroffen zu haben. Die Frist für die Arbeit der Experten verlängerten die Minister bis zum 31. 10., um ihnen Zeit für die Abfassung des Abschlußberichtes zu geben, der auf einer nächsten Außenministerkonferenz Ende November vorliegen sollte. Zugleich erinnerten sie das Spaak-Komitee noch einmal daran, seine Aufgabe nicht in der Formulierung neuer Vorschläge zur wirtschaftlichen Integration, sondern der möglichst unparteiischen Prüfung der Sachfragen zu sehen ${ }^{171}$.

Ein wichtiger Grund für die sich anbahnende Veränderung der französischen Politik war die sich abzeichnende Verständigungspolitik zwischen den Weltmächten im Zeichen des Geistes von Genf. Im Kommuniqué der Konferenz von Nordwijk kleideten die Minister diesen Sachverhalt in die Worte, ,daß die politische und wirtschaftliche Entwicklung in Europa und in der gesamten Welt mehr denn je die Konzentration aller Bestrebungen erfordert, die geeignet sind, das begonnene Werk zum Erfolg zu führen"172. Wie die Bundesrepublik zog auch Frankreich aus den weltpolitischen Veränderungen den Schluß, die eigene Position durch die engere europäische Zusammenarbeit stärken zu müssen. Hinsichtlich des zentralen Streitpunkts des Gemeinsamen Marktes bewegte sich die französische Regierung dennoch nur millimeterweise von der Stelle. Als die französischen Vertreter in Brüssel unter der Federführung von Uri in einer Aufzeichnung die These aufstellte, daß die Harmonisierung der Sozial-, Wirtschafts- und Finanzpolitik „,n'est pas une des conditions préalables du marché commun “", schrillten im Quai d'Orsay die Alarm-

169 Ebd., Bl. 104 f., Aufzeichnung ders., 2. 9.1955 (Konzept FV).

170 S. ebd., Bl. 117 f., Wormser an London etc., Tel. 11718/20 etc., 8. 9. 1955; ders. an Valéry, Aufzeichnung, 7. 9. 1955, in: DDF 1955, Bd. 2, S. 437-439.

17 S. PA, Abt. 2, Bd. 903, Bl. 130-153, Konferenz der EGKS-Außenminister vom 6. 9. 1955, MAE 322d/55, 28. 9. 1955, Entwurf; ebd., Bd. 899, Bl. 159-189, Bericht des AA und BMWi über den Stand der Verhandlungen der Brüsseler Konferenz, 27. 10. 1955; Küsters, Gründung, S. $157 \mathrm{f}$.

172 Kommuniqué der Konferenz der EGKS-Außenminister, 6. 9. 1955, in: Bulletin 1955, S. 1423. 
glocken. Denn diese "négation" der bisherigen Position schien aus politischen wie psychologischen Gründen äußerst bedenklich, drohte sie doch die Position der übrigen Delegationen zu verhärten und ihre Weigerung zur Akzeptierung einer „harmonisation préalable à l'institution du marché commun" zu stärken ${ }^{173}$.

In der Bonner Delegation wurden diese Differenzen zwischen ihren europafreundlichen französischen Kollegen und der zögernden Regierung in Paris sehr wohl gespürt und der Rücksichtnahme auf die bevorstehenden Parlamentswahlen zugeschrieben. Vor die Option gestellt, einer Konstruktion zuzustimmen, die nur „den Schein einer europäischen Lösung" wahrte, und den Urnengang abzuwarten, schien Frankreich die entscheidenden Festlegungen notfalls erst nach den Wahlen treffen zu wollen ${ }^{174}$. Sein weiteres Vorgehen gab den deutschen Befürchtungen recht. Am 12. 10. beschloß der Conseil des Ministres neue Richtlinien für Gaillard ${ }^{175}$, die sowohl die europafreundlichen Kreise wie die Europagegner zufrieden stellen sollten. Die in Brüssel am 14. 10. in Form eines Memorandums präsentierten Vorstellungen sahen die Schaffung eines Gemeinsamen Marktes zur Beruhigung der Skeptiker in einem Zeitraum von zehn bis fünfzehn Jahren mit einer ersten Periode von vier Jahren sowie die Abfederung durch einen Anpassungsund einen Investitionsfonds vor. Zugleich betonte das Dokument die Gleichzeitigkeit des Abbaus von Zöllen und Kontingenten mit der sozialen Harmonisierung, zu denen es die Angleichung der Wochenarbeitslöhne, Vergütung der Überstunden und Dauer des bezahlten Urlaubs sowie Gleichheit der Löhne für Männer und Frauen zählte. Außerdem schloß es die Einbeziehung des Agrarsektors in den Gemeinsamen Markt im Prinzip aus. Um die europafreundlichen Politiker zufriedenzustellen, stellte das Memorandum im dritten Teil supranationale Organe in Aussicht, ohne den Begriff tatsächlich zu benutzen, und schränkte die Teilnahmerzahl auf die Sechsergemeinschaft ein ${ }^{176}$.

Paris war sich dabei bewußt, daß wichtige Passagen dieses Dokuments für die Partner unannehmbar waren. Andere Abschnitte würden hingegen in Frankreich auf Ablehnung stoßen, und zwar bei jenen Kräften, die ihre Hoffnungen auf die nahende Genfer Außenministerkonferenz setzten, die die "construction artificielle et contre nature dénommée ,Petite Europe “" verteufelten und lautstark forderten, „de faire machine arrière "177. Die Vorlage eines Befürworter wie Gegner der europäischen Integration gleichermaßen ins Visier nehmenden Konzepts schien der Regierung dennoch unumgänglich, weil man zu einer zentralen $\mathrm{Zu}$ kunftsfrage Stellung beziehen mußte und die Brüsseler Verhandlungen nicht scheitern lassen durfte. Wohl wissend, jetzt von der ursprünglichen Position in der Frage des Gemeinsamen Marktes abgewichen zu sein, gedachte man diese „concession“ gegen Zugeständnisse der Partner in den Bereichen Atomenergie und Luftfahrt einzutauschen ${ }^{178}$.

173 AMAE, DE-CE, Bd. 612, Bl. 132-134, Aufzeichnung der Unterabt. für wirtschaftliche Kooperation im MAE an Kabinett des Ministers, 19.9.1955 (Konzept RSL).

174 PA, Ref. 200, AZ 85.11/0, Bd. 1, Aufzeichnung, 29. 9. 1955.

175 S. ebd., Abt. 2, Bd. 899, Bl. 5-7, von Maltzan an AA, 305a/W 1854/55, 13. 10.1955.

176 S. Memorandum der französischen Delegation, Nr. 337, 14. 10. 1955, in: DDF 1955, Bd. 2, S. 660 663; Küsters, Gründung, S. 160.

177 AMAE, DE-CE, Bd. 612, Bl. 161-172, „Fin de relance“, 31. 10. 1955.

178 Aufzeichnung Valéry, 13. 10. 1955, in: DDF 1955, Bd. 2, S. 658-660, hier S. 660. 
Um seinen Außenministerkollegen den Abschlußbericht termingerecht vorlegen zu können, wies Spaak die Fachgremien am 3. 10. an, ihre Untersuchungen bis zum 15. des Monats abzuschließen. Als ihm die Berichte der Ausschüsse für den Gemeinsamen Markt, Verkehr und für die Klassische Energie vorlagen, sah er rasch, daß die Meinungsverschiedenheiten in den Fragen der Festsetzung von Terminen für die einzelnen Etappen zum Gemeinsamen Markt, der Einbeziehung der Landwirtschaft, der Ausgestaltung von Anpassungs- und Investitionsfonds, der Zusammenarbeit auf dem Energiesektor oder bezüglich des nach der Konferenz von Nordwijk intensiv behandelten Problems des institutionellen Systems ${ }^{179}$ keineswegs beseitigt waren. Am grundsätzlichen Frontverlauf hatte sich nichts geändert: Frankreich war vornehmlich an der Atomgemeinschaft interessiert, während die übrigen Fünf eher dem Gemeinsamen Markt zuneigten. Pariser Hoffnungen, zunächst einmal die eigenen Atominteressen durchzusetzen, parierten die Partner mit der Forderung paralleler Fortschritte in beiden Sektoren ${ }^{180}$.

Der Ausschuß für Kernenergie hatte seine Arbeit noch gar nicht beendet, weil es zwischen der deutschen und der französischen Delegation zu einem tiefen Dissens gekommen war. Armand, der Ausschußvorsitzende, hatte Anfang Oktober eine Zwischenbilanz vorgelegt, mit der er die europafreundliche Position im Ausschuß, der er persönlich auch zuneigte, mit der Haltung der Gegner der europäischen Nukleargemeinschaft in Frankreich in Einklang zu bringen versuchte. Nach seinem Konzept sollte EURATOM außer einer gemeinsamen Isotopentrennanlage vor allem einen Alleinanspruch für die Belieferung seiner Mitglieder mit Kernbrennstoffen und Erzen besitzen, was aber auf erhebliche Bonner Vorbehalte traf ${ }^{181}$. Mit ihrer Kritik an einem derartigen Versorgungsmonopol trug die deutsche Delegation der Tatsache Rechnung, $\mathrm{da} \beta$ in Bonn soeben ein Atomministerium unter Franz Josef Strauß geschaffen worden war, das die „Vermeidung monopolistischer Konstruktionen für die Beschaffung und Verteilung der Kernstoffe und für die Behandlung des gewerblichen Eigentums" forderte. Während das Bundeswirtschaftsministerium diesen Überlegungen weitgehend beipflichtete, hielt das Auswärtige Amt ein Eingehen auf die französischen Überlegungen aus gesamtpolitischen Gründen für wichtiger als ein Beharren auf die nicht zuletzt von der Industrie geteilten Bedenken. Allerdings vertrat auch Strauß, der seine Position offenbar noch nicht so definitiv festgelegt hatte wie Erhard, die Auffassung, die Wirtschaft habe sich "den großen politischen Entscheidungen unterzuordnen"182. Dies bedeutete für ihn aber keineswegs, dem Auswärtigen Amt die Federführung in der Atomfrage zu überlassen, was von Brentano, Hallstein und Ophüls wiederum dazu brachte, durch die Einschaltung amerikanischer Diplomaten Druck auf den unbotmäßigen Minister ausüben und ihn

$179 \mathrm{Vgl}$. Küsters, Gründung, S. 197-202.

180 S. PA, Abt. 2, Bd. 899, Bl. 159-189, Bericht des AA und BMWi über den Stand der Verhandlungen der Brüsseler Konferenz, 27. 10. 1955; Aufzeichnung der Unterabt. für wirtschaftliche Kooperation im MAE, 14. 11. 1955, in: DDF 1955, Bd. 2, S. 805-808; Guillen, La France et la négociation des traités de Rome, S. 516; Küsters, Gründung, S. 203.

181 Vgl. Eckert, Kernenergie, S. 320; Weilemann, Anfänge, S. 42-46.

182 PA, Abt. 2, Bd. 899, Bl. 101-108, Ressortbesprechung vom 2. 11. 1955, 210-225/00/12872/55, 7. 11. 1955, Streng vertraulich; s.a. AMAE, NUOI, Bd. 631, de Margerie an MAE, Tel. 4409/11, 15. 11. 1955, Réservé, Priorité. 
auf ihre integrationsfreundliche Atompolitik einschwenken $\mathrm{zu}$ lassen ${ }^{183}$. Und dennoch: Als Armand am 5. 11. den im großen und ganzen seine Handschrift tragenden Abschlußbericht seines Ausschusses vorlegte, hatte die deutsche Delegation ungeachtet der von Spaak und Monnet in aller Eile organisierten amerikanischen Einflußnahme keine definitive Stellungnahme abgegeben, da ihr die Zeit fehlte und in Bonn die Meinung vorherrschte, das Dokument besitze ohnehin keine Bindewirkung für die Bundesregierung ${ }^{184}$.

Um trotzdem zu einem einheitlichen Gesamtbericht zu gelangen, beschloß Spaak, mit einem gestrafften Beratungsgremium unter Mißachtung seines in Messina fixierten Auftrags Lösungsvorschläge in den strittigen Fragen auszuarbeiten. Er konzentrierte die Arbeit auf die Delegationsleiter und zog zwei weitere Experten hinzu: Pierre Uri, der ihm von Monnet empfohlen worden war, und Hans von der Groeben, der die deutschen Bedenken gegen den Franzosen ausgleichen sollte ${ }^{185}$. Anfang November nahm der verkleinerte Regierungsausschuß die Arbeit auf. Sein Erfolg hing nicht zuletzt von den Instruktionen ab, die aus Bonn und Paris kamen.

\section{„Redonner une nouvelle vie à l'idée européenne“}

Im Kanzleramt mußte man sich mittlerweile eingestehen, daß die Gegner der eigenen Europapolitik nicht mehr wie in den Jahren zuvor im sozialdemokratischen Lager, sondern in der Union saßen. Mit dem Eintritt in Monnets neues „Aktionskomitee für die Vereinigten Staaten von Europa“ im Oktober markierte die SPD öffentlich eine europapolitische Schwenkung und legte den Grundstein für einen außenpolitischen Grundkonsens mit der Koalition ${ }^{186}$. Innerhalb der Regierung konnte von einem derartigen Einvernehmen über den Kurs der deutschen Europapolitik nicht die Rede sein. Das anhaltende Gezerre zwischen dem Auswärtigen Amt und dem Bundeswirtschaftsministerium, in das sich auch noch die Ministerien für wirtschaftliche Zusammenarbeit, der Finanzen und für Atomfragen einmischten ${ }^{187}$, ließ die europafreundlichen Kreise in Bonn mobil werden. Dazu gehörte auch Ministerialdirigent Karl Carstens, der neue Leiter der Unterabteilung Zwischen- und überstaatliche Organisationen im Auswärtigen Amt.

Am 14. 12. 1914 als Sohn eines Studienrats in Bremen geboren, arbeitete Carstens nach dem Studium der Rechte und der Politischen Wissenschaften sowie dem Wehrdienst seit 1944 als Rechtsanwalt, dann als Landesanwalt beim Bremer Senat. Parallel zu seiner 1949 begonnenen Tätigkeit als Leiter der Vertretung Bre-

183 S. Conant an Dep. of State, Tel. 1468, 4. 11. 1955, Secret, in: FRUS 1955-1957, Bd. 4, S. 344-346; Eckert, Kernenergie, S. 320f. Zur Atompolitik von Strauß vgl. Fischer, Atomenergie, S. $260-282$.

184 S. PA, Abt. 2, Bd. 899, Bl. 101-108, Ressortbesprechung vom 2.11. 1955, 210-225/00/12872/55,

7. 11. 1955, Streng vertraulich; ebd., Bl. 96-100, Ressortbesprechung vom 3. 11. 1955, 210-225/00/ 12872/55 II, 7. 11. 1955, Streng vertraulich; Bossuat, Jean Monnet, S. 322 f.; Fischer, Atomenergie, S. 276; Schröder, Jean Monnet, S. 404-417; Weilemann, Anfänge, S. $46 \mathrm{f}$.

185 S. PA, Abt. 2, Bd. 899, Bl. 10 f., Müller-Roschach an Hallstein, Aufzeichnung 210-225/00/11773/ 55, 14. 10. 1955; von der Groeben, Deutschland, S. 276; Spaak, Memoiren, S. 317; Dumoulin, Travaux, S. 203-205; Küsters, Gründung, S. $204 \mathrm{f}$.

186 Vgl. Hrbek, SPD, S. 256f.; Paterson, SPD, S. 123-125. Zur Gründung des Aktionskomitees s. Monnet, Erinnerungen, 513-528; Duchêne, Jean Monnet, S. 284-288; Roussel, Jean Monnet, S. 689-697; Schröder, Jean Monnet, S. 410-413.

187 Vgl. Küsters, Streit, S. 353-358. 
mens am Sitz der Bundesregierung, seit 1952 als Bevollmächtigter der Freien Hansestadt Bremen beim Bund, nahm er ab 1950 einen Lehrauftrag an der Universität zu Köln wahr. 1952 habilitierte er sich für Staats- und Völkerrecht. Obwohl er im Herbst 1954 in das Auswärtige Amt wechselte und bis August 1955 als Ständiger Vertreter der Bundesrepublik beim Europarat wirkte, übte er seine Lehrtätigkeit weiter aus. Nach der Rückkehr in die Zentrale übernahm Carstens als Ministerialdirigent für drei Jahre die Unterabteilung Zwischen- und überstaatliche Organisationen und stieg Ende August 1958 als Ministerialdirektor zum Leiter der Politischen Abteilung West 1 auf. Nach der Schaffung eines zweiten Staatssekretärpostens wurde er am 28. 7. 1960 zum Staatssekretär im Auswärtigen Amt ernannt. Im selben Jahr erhielt Carstens eine Professur für Staatsrecht in Köln. Anfang Mai 1961 übernahm er von Hilger van Scherpenberg die Position des Staatssekretärs des Auswärtigen Amts ${ }^{188}$.

Nach außen konservativ und spröde wirkend, war der nachmalige Bundespräsident in seinem Verantwortungsbereich nicht nur auf Effektivität und Pflichtbewußtsein, sondern auch auf ein gutes „Betriebsklima“ bedacht. Trotz aller Loyalität gegenüber Vorgesetzten bewahrte er sich stets sein von ausgeprägtem Selbstbewußtsein geformtes eigenständiges Urteil und eine liberale Einstellung gegenüber politisch Andersdenkenden; sie erlaubte es ihm nicht nur, das SPD-regierte Bremen beim Bund zu vertreten, sondern auch im Auswärtigen Amt „ein ausgesprochenes Vertrauensverhältnis" zur Opposition zu pflegen"189. Außenpolitisch gesehen, war er wohl ein gemäßigter ,Atlantiker‘. Trotz aller Befürwortung der deutsch-französischen Versöhnung mißbilligte er eindeutig ein Exklusivbündnis mit Frankreich: „Wenn aber der Fall eintreten sollte, daß wir Deutschen gezwungen wären, zwischen Frankreich und den USA zu wählen, dann müßten wir uns für die USA entscheiden" $" 190$.

In der Europapolitik unterstützte er klar die Linie seines Hauses. Der ständigen Querelen zwischen den beteiligten Ressorts überdrüssig, empfahl der Ministerialdirigent am 9. 11. Staatssekretär Hallstein ein persönliches Gespräch zwischen dem Kanzler und den betroffenen Ministern mit dem Ziel, „die politische Bedeutung der Brüsseler Integrationsverhandlungen darzulegen und ihnen gegenüber $z \mathfrak{u}$ erkennen zu geben, daß die positive Beurteilung des mit den Verhandlungen erstrebten Ziels als eine Richtlinie der Politik anzusehen sei"191. Von einem solchen demonstrativen Schritt wollte Adenauer zu diesem Zeitpunkt offenbar noch nichts wissen. Eine schwere Lungenentzündung, die ihn von Anfang Oktober bis Ende November ans Bett fesselte ${ }^{192}$, erlaubte jetzt wohl auch kaum einen derartigen innergouvernementalen Kraftakt, obwohl auch der Kanzler das "rapide“ gesunkene Vertrauen der Welt zu Deutschland auf die Tatsache zurückführte, daß die Intransigenz einiger Ministerien in der Integrationsfrage im Ausland den Ein-

\footnotetext{
${ }_{188} \mathrm{Zu}$ Person und Politik von Carstens s. Carstens, Erinnerungen; ders., Politische Führung.

189 Ders., Erinnerungen, S. 218.

190 Ebd., S. 262

191 PA, Abt. 2, Bd. 899, Bl. 125, Carstens an Hallstein, Aufzeichnung 225-00/12977/55, 9. 11. 1955.

192 Vgl. Fischer, Atomenergie, S. 275 f.; Schwarz, Adenauer, Bd. 2, S. 234.
} 
druck hervorgerufen hatte, „die Deutschen verzögern absichtlich diese ganze Sache, um sich eine Tür zum Osten offenzuhalten “193.

Allerdings sah er sehr wohl Handlungsbedarf. Die Enttäuschung über die ersten Kontakte zu Moskau, die national geprägte Kreise in die Versuchung zu führen drohte, direkte Verhandlungen mit dem Kreml anzustreben ${ }^{194}$, die Stagnation der Wiedervereinigungspolitik sowie der Wunsch, den Westen zu beruhigen, bewogen ihn dazu, „à redonner une nouvelle vie à l'idée européenne" 195 . Um die in Brüssel entstandenen Schwierigkeiten politisch zu lösen, bedurfte es seiner Meinung nach vor allem des Einvernehmens mit Paris. Ein Krankenbesuch Pinays, der ihn am 13.11. in Rhöndorf aufzusuchen beabsichtigte, bot eine günstige Gelegenheit. Die Neubelebung der europäischen Idee, so betonte Hallstein wenige Tage zuvor gegenüber dem französischen Geschäftsträger zur Einstimmung der Gespräche, sei schon deshalb notwendig, um das Vakuum zu füllen, das sich nach der Genfer Außenministerkonferenz ergeben habe ${ }^{196}$. Kurz darauf ließ der Staatssekretär in Paris wissen, die Brüsseler Gespräche hätten keine genügenden Fortschritte erbracht. Zur Mobilisierung der öffentlichen Meinung sei es jetzt erforderlich, „se replacer résolument sur le terrain politique“. In diesem Zusammenhang regte er an, möglichst bald den Pinay-Plan eines Conseil fédéral européen als Konsultationsorgan zu studieren sowie den Gedanken einer Direktwahl zur Montanversammlung aufzunehmen ${ }^{197}$.

Ohne auf diese Überlegungen näher einzugehen, unterstrich auch Adenauer gegenüber Pinay, es sei jetzt hohe Zeit, „de relancer l'idée européenne et celle-ci doit essentiellement se fonder sur la coopération franco-allemande"198. Dies schien um so notwendiger, als der Ausgang des Saarreferendums am 23. 10. ganz offensichtlich „die Europäer in Frankreich entmutigt und die Antieuropäer ermutigt" hatte ${ }^{199}$. Der Bonner Vorstoß fand in Paris starke Unterstützung, nicht zuletzt aus deutschlandpolitischen Überlegungen. Noch gab es zwar in wirtschaftlichen, militärischen oder politisch-parlamentarischen Kreisen keine Anzeichen dafür, daß die Stagnation in der Wiedervereinigungsfrage in eine "politique de rechange" umschlagen könne. Dennoch schien es zunehmend wichtiger, Deutschland fester in den Westen einzubinden und die „relance européenne“ zu forcieren ${ }^{200}$. Nach dem Fehlschlag von Genf mußte den Deutschen eine neue Perspektive aufgezeigt werden, und dazu bot sich vor allem die europäische Idee an. Zugegeben, die hochtrabenden Pläne eines europäischen Bundesstaates oder eines direkt gewähl-

193 Adenauer, Teegespräche 1955-1958, S. 32 u. 37, Wortprotokoll, 13. 12.1955.

${ }_{194}$ S. Kap. IV.1.1; de Margerie an Pinay, Tel. 4345/48, 11.11. 1955, Réservé, in: DDF 1955, Bd. 2, S. $794 f$.

195 AMAE, Europe 1944-1960, Allemagne, Bd. 355, Bl. 138-139, ders. an MAE, Tel. 4488/96, 19. 11. 1955.

196 S. ders. an Pinay, Tel. 4345/48, 11. 11. 1955, Réservé, in: DDF 1955, Bd. 2, S. $794 \mathrm{f}$.

197 AMAE, Europe 1944-1960, Allemagne, Bd. 390, Bl. 178-179, ders. an MAE, Tel. 378/83, 12.11. 1955, Extrême urgence.

198 Unterredung zwischen Adenauer und Pinay vom 13.11. 1955, in: DDF 1955, Annexes, Bd. 2, S. 485-487, hier S. 485; s.a. AMAE, Europe 1944-1960, Allemagne, Bd. 390, Bl. 183-185, de Margerie an MAE, Tel. 4371/86, 13. 11. 1955, Priorité, Réservé; Blankenhorn, Verständnis, S. 239, Tb. 13. 11. 1955.

199 PA, BStS, Bd. 229, Erklärung Hallsteins in einem Informationsgespräch vom 13.11. 1955; zum Saarreferendum s. Kap. IV.3.1.

200 De Margerie an Pinay, Nr. 1814, 22. 12. 1955, in: BDFD I, S. 508-514, hier S. 509 u. 513. 
ten europäischen Parlaments lagen inzwischen auf Eis, aber es gab durchaus eine Reihe von Möglichkeiten, „de s'engager dans la voie de réalisations concrètes d'ordre économique". Angesichts der in Brüssel zutage getretenen Probleme befürchtete man allerdings an der Seine, daß die wirtschaftliche Kooperation ihre Früchte nicht sofort tragen könne. Folglich schien es das beste, sich zunächst auf die bilaterale Ebene und nicht die Sechsergemeinschaft zu konzentrieren. In dem Maße, wie zweiseitige Projekte im zivilen und militärischen Flugzeugbau oder in der Kernenergie das Vertrauen in die Wirksamkeit der europäischen Idee wiederbelebten, so lautete die Philosophie, sei es auch möglich, die größeren Pläne wie den Gemeinsamen Markt oder die Atomgemeinschaft umzusetzen. Angesichts einer offenbar beginnenden Öffnung der SPD-Opposition für derartige Pläne hielt es die französische Diplomatie für entscheidend wichtig, ihre Kontakte nicht auf die Bundesregierung zu beschränken. Als Ziel visierte sie nun an, die Entwicklung in Deutschland mit vielfältigen Mitteln zu beeinflussen, „pour donner davantage tant à l'Allemagne qu'à la France le sentiment de la communauté de leur destin"201. Um die deutsche Sozialdemokratie noch stärker für die Westbindung der Bonner Republik im Rahmen der europäischen Integration oder der bilateralen Zusammenarbeit zu gewinnen, operierte Paris vornehmlich mit den Argumenten, sie zerstöre mit einer Wende in ihrer Europapolitik das bisherige Monopol der Union und bremse den mit der wirtschaftlichen Stärke wachsenden Egoismus der deutschen Industrie 202.

$\mathrm{Ob}$ der deutsche und französische Wille zu wirklichen Fortschritten in der europäischen Politik tatsächlich umgesetzt werden konnte, war keineswegs sicher. Am 1. 12. mußten die Arbeiten in Brüssel unterbrochen werden, weil zwei Faktoren den Fortgang in Frage stellten: die Handlungsunfähigkeit Frankreichs nach dem Sturz der Regierung Faure am 29. 11.203 und die etappenweise Ankündigung Großbritanniens im November und Dezember, an den Gemeinschaftsprojekten nicht teilhaben zu wollen ${ }^{204}$, was sicherlich nicht nur in Paris als neuerlicher Beweis gehandelt wurden, „que les Anglais n'ont obéi qu’à des habitudes enracinées et à la conception qu'ils se font de leurs intérêt commerciaux" 205. Der weitere Gang der Entwicklung hing nun vom Ausgang der Parlamentswahlen in Frankreich $\mathrm{ab}$, und sie trugen nicht gerade zur Stabilisierung der innenpolitischen Verhältnisse bei. Als große Sieger galten die Extremisten von rechts und links. Die Sozialisten gewannen zwar die Regierungsmacht, aber keine stabile Mehrheit. Nach wochenlangem Tauziehen bildete Guy Mollet Anfang Februar eine Mitte-LinksKoalition, die sich auf weniger als 200 der 595 Abgeordneten stützen konnte ${ }^{206}$.

201 Aufzeichnung der Unterabt. Zentraleuropa im MAE, 21.11. 1955, Confidentiel, in: DDF 1955, Bd. 2, S. 836-840, hier S. 838 u. 840.

202 S. AMAE, Europe 1944-1960, Allemagne, Bd. 390, Bl. 224-26, dies. an Jurgensen, Aufzeichnung, 12. 12. 1955

$203 \mathrm{Vgl.} \mathrm{Kap.} \mathrm{IV.1.2.}$

204 S. AMAE, DE-CE, Bd. 701, Bl. 31 f., MAE an Bonn etc., Tel., 13. 12. 1955; ebd., Bl. 33-35, Massigli an Chauvel, 13. 12. 1955; ebd., Bl. 44, Memorandum Frankreichs an Großbritannien, 22. 12. 1955; Adenauer, Erinnerungen 1955-1959, S. 255-258; Spaak, Memoiren, S. 308 f.; Bullen, Great Britain, S. 333-338; Kaiser, Großbritannien, S. 63-67; Küsters, Gründung, S. 205-215.

${ }^{205}$ AMAE, DE-CE, Bd. 701, Bl. 38 f., Chauvel an Massigli, 20. 12. 1955.

206 Vgl. Kap. IV.1.2. 
Vom europäischen Blickwinkel aus betrachtet, mochte die Ernennung Mollets „die beste Lösung" sein ${ }^{207}$. War es aber auch eine gute Lösung? Gewiß, hätte Staatspräsident Coty statt Mollet Mendès France zum Président du Conseil ernannt, wären erhebliche Probleme zu erwarten gewesen ${ }^{208}$. Mollet besaß solide europäische Überzeugungen, und sein Außenminister Pineau galt als „pro-européen"209, bestärkt von Coty, der den ihm sehr nahestehenden Chef des Quai d'Orsay trotz seiner ansonsten sehr zurückhaltenden Amtsführung nach dem Regierungswechsel den Auftrag gab, „de construire l'Europe à tout prix“210. Angesichts der fortbestehenden innen- wie außenpolitischen Belastungen und einer antieuropäischen „opposition très décidé“ in der neuen Assemblée Nationale bot das Minderheitenkabinett indes keinen Grund zum Optimismus ${ }^{211}$. Zwar verteidigte es den europäischen Zusammenschluß „stärker als alle bisherigen“ Regierungen, doch entwickelte sich das Klima in Frankreich insgesamt eher europafeindlich. „Das unbehagliche Gefühl, als viel schwächerer Partner mit dem großen Titanen im Norden in eine enge Gemeinschaft zu treten und bei der wachsenden eigenen Schwäche von diesem Partner schließlich gänzlich dirigiert zu werden, nimmt ständig zu“", meldete Blankenhorn Anfang Februar aus Paris²12. Blieb dem Président du Conseil noch genügend Spielraum, um die Stärkung der westeuropäischen Staaten, also die Zusammenfassung ihres wirtschaftlichen und politischen Potentials anzugehen? Oder zwang die innenpolitische Konstellation dazu, sich auf die Durchsetzung französischer Machtpolitik zu beschränken, ummäntelt mit einem europäischen Gewande?

Es war wohl diese Perspektive, die Adenauer, nach sechswöchiger Krankheit wieder genesen, noch vor der Bildung der Regierung Mollet dazu brachte, jetzt dem Rat von Carstens zu folgen und mit einem Machtwort den Kurs der Bonner Europapolitik par ordre du mufti zu fixieren. Die enttäuschten Hoffnungen auf eine wirkliche Entspannung zwischen Ost und West nach der ergebnislosen Genfer Außenministerkonferenz im Oktober, nicht verstummende Klagen europäischer Politiker über die Verweigerungshaltung einiger Bonner Minister ${ }^{213}$ und das Drängen der Amerikaner auf weitere Integrationsschritte im ökonomischen wie atompolitischen Sektor ${ }^{214}$ beförderten diesen Beschluß zweifellos. Am 19. 1. 1956 ordnete der Kanzler in einem Schreiben an sämtliche Bundesminister an, die Resolution von Messina „entschlossen und unverfälscht durch[zu]führen“. Unter keinen Umständen, so hieß es in dem Brief weiter, dürfe die europäische Integra-

207 PA, Abg.-Liste Ministerbüro, Bd. 155, Unterredung zwischen von Brentano und Monnet vom 9. 1.1956.

208 Vgl. Diskussionsbeitrag Pineaus in: Serra (Hg.), Rilancio, S. 281.

209 Gerbet, Construction, S. 179.

210 Diskussionsbeitrag Pineaus in: Serra (Hg.), Rilancio, S. 281; zur Beziehung zwischen Pineau und Coty vgl. de Baecque, René Coty, S. 216.

211 Gerbet, Construction, S. 179.

212 PA, BStS, Bd. 281, Blankenhorn an Hallstein, 9. 2. 1956; s.a. Blankenhorn, Verständnis, S. 246 f., Tb. 3. 2. 1956.

${ }_{213}$ S. PA, BStS, Bd. 229, Informationsgespräch mit Hallstein vom 15.11. 1955; Dulles an Dep. of State, Tel. Secto 19, 17. 12. 1955, Secret, Limit Distribution, in: FRUS 1955-1957, Bd. 4, S. 369371; Adenauer, Teegespräche 1955-1958, S. 37, Wortprotokoll, 13. 12. 1955; Eckert, Kernenergie, S. 322 f.

214 Vgl. die Dokumente in: FRUS 1955-1957, Bd. 4, S. 332-387; di Nolfo, Stati Uniti. 
tion „durch unser Widerstreben oder unser Zögern“ scheitern. Einmal mehr klang der instrumentelle Charakter von Adenauers Europaphilosophie an: Wenn die Integration gelinge, könne die Bundesrepublik das Gewicht des einigen Europa in die Ost-West-Verhandlungen über die europäische Sicherheit und die Wiedervereinigung Deutschlands in die Waagschale werfen ${ }^{215}$. Des Kanzlers Richtlinie zur Europapolitik besaß zwei Adressaten: das eigene Kabinett, in dem die unbotmäBigen Minister auf Linie gebracht, und die Öffentlichkeit, die über die Arbeitsgemeinschaft Demokratischer Kreise beeinflußt werden sollten ${ }^{216}$.

Wie Adenauer so ordnete auch Mollet nun die Fortsetzung der Brüsseler Verhandlungen in Richtung auf einen Gemeinsamen Markt und eine Atomgemeinschaft an, behielt aber den von Pinay vertretenen Kurs des Ausgleichens zwischen den widerstreitenden Positionen bei. Gewiß, das MRP Schumans und Teitgens und auch die UDSR Plevens forderten vehement die Realisierung der Messina-Initiative, wobei das EURATOM-Projekt für sie weitgehend die Priorität besaß217. Ganz anders sah es demgegenüber in den übrigen Parteien aus. Im Parti Radical bewerteten zumindest die Anhänger von Mendès France diese Politik als Gefahr für Frankreichs Wohlstand und Unabhängigkeit ${ }^{218}$. In der SFIO war die Meinung gespalten, wohingegen die Sozialrepublikaner und Kommunisten der europäischen Einigung dezidiert ablehnend gegenüberstanden ${ }^{219}$.

Pineau vertrat zur Messina-Resolution einen insgesamt „reserviert-skeptischen Standpunkt", wobei er sein Hauptinteresse klar auf EURATOM ausrichtete220. Mollet, noch im Juli 1955 per Akklamation als Präsident der Beratenden Versammlung des Europarates wiedergewählt, ging der Ruf voraus, ein entschiedener Europäer zu sein. Kurz vor den Parlamentswahlen hatte er ihn noch mit seinem Beitritt zu Monnets Aktionskomitee und mit einem aufsehenerregenden Artikel in „Le Monde“ untermauert, in dem er die Wirtschaftsintegration zum Ziel der Republikanischen Front erklärte 221 . In seiner Regierungserklärung vom 31. 1. sagte der Président du Conseil dem Brüsseler Ausschuß seine volle Unterstützung zu, doch seine diesbezüglichen Ambitionen wirkten recht einseitig zugunsten der Atompolitik ausgeprägt. Während er in der Frage der Atomgemeinschaft rasche Fortschritte zu erzielen und einen Vertrag noch vor dem Sommer zu unterzeichnen wünschte, machte er die Errichtung des Gemeinsamen Marktes von einer Reihe sozialpolitischer Maßnahmen abhängig222.

\section{„Zeichen des Kompromisses“: Der „Spaak-Bericht“}

Mittlerweile hatten die Delegationsleiter des von der Messina-Konferenz eingesetzten Regierungskomitees ihre Arbeiten fortgesetzt und für die Zollunion bzw.

\footnotetext{
215 Adenauer an die Bundesminister, 19. 1. 1956, in: BDFD I, S. 596-598, hier S. 597 u. 596.

216 S. Jahn, An Adenauers Seite, S. 330.

217 S. Bichet, Démocratie chrétienne, S. 317-321; Bougeard, René Pleven, S. 281; Brunet, MRP; Irving, Christian Democracy, S. 189-191; Latte, Europapolitik, S. 108-114.

218 Vgl. O'Neill, Radical Party, S. 91-96.

219 Vgl. Latte, Europapolitik, S. 101-108; Quilliot, S. F.I.O., S. 582-586.

220 Küsters, Gründung, S. 220; vgl. Pineau/Rimbaud, Grand Pari.

221 S. Artikel Mollets, in: „Le Monde“, 28. 12. 1955; Lefebvre, Guy Mollet, S. 168.

222 S. Regierungserklärung Mollets, 31. 1. 1956, in: JO, Ass. Nat., Déb. parl. 1956, Bd. 1, S. 135-139; in deutscher Ubersetzung auszugsweise in: EA 1956, S. 8646-8650; Lefebvre, Guy Mollet, S. 269.
} 
den Gemeinsamen Markt mit Ausnahme des Landwirtschaftsproblems relativ zügig Lösungen gefunden ${ }^{223}$. Weitaus problematischer verliefen die Beratungen über EURATOM, nachdem die OEEC die Schaffung eines Direktoriums für Atomenergie angeregt hatte, dem die Gegner einer Atomgemeinschaft à six in der Bundesrepublik, aber auch in Frankreich und Großbritannien zuneigten 224. Monnets Aktionskomitee verabschiedete daraufhin auf der konstituierenden Sitzung Mitte Januar eine Resolution und eine Gemeinsame Erklärung, mit der der Atomgemeinschaft eine klare Priorität vor dem Gemeinsamen Markt eingeräumt wurde. Indem das Gremium die Gemeinschaft darüber hinaus auf die rein zivile Nutzung der Atomenergie beschränkte, hoffte Monnet, das Problem der Nichtdiskriminierung der Bundesrepublik lösen und die Zustimmung der Sozialdemokraten erleichtern zu können ${ }^{225}$. Rückendeckung bekam sein Ansatz nicht zuletzt von den Amerikanern, die EURATOM und den Gemeinsamen Markt unterstützten, EURATOM aber als wichtiger betrachteten, da es ihnen vornehmlich darum ging, die Entwicklung der europäischen Atompolitik zu kontrollieren und die militärische Nutzung möglichst zu verhindern. Eine europäische Atomgemeinschaft schien dazu das beste Mittel226.

Mollet schloß sich der von Monnet empfohlenen Selbstbeschränkung an ${ }^{227}$ und zog damit den Verdruß der Anhänger einer nationalen französischen Atommacht auf sich. General Billotte, der scheidende Verteidigungsminister, sprach diesen Kreisen zweifellos aus der Seele, als er die noch im Amt befindliche Regierung Faure am 24. 1. eindringlich auf die Folgen eines Nuklearwaffenverzichts hinwies: Inferiorität gegenüber den Atommächten und Aufgabe des durch die Pariser Verträge gegebenen „avantage essentiel“ gegenüber der Bundesrepublik ${ }^{228}$. Auch de Gaulle schaltete sich jetzt in die Diskussion ein und warnte vor dem Verlust nationaler Unabhängigkeit als Konsequenz einer integrierten Atomgemeinschaft. Selbst Anhänger der Europaidee wie René Pleven oder Maurice Faure äußerten Bedenken. Bedrängt von einigen seiner Minister, gab Mollet nach der Regierungsbildung schließlich nach und instruierte Gaillard, in Brüssel die alte These zu verteidigen, daß EURATOM die militärischen Ambitionen Frankreichs nicht beeinträchtigen dürfe ${ }^{229}$. Mit dieser Betonung der französischen Interessen entfachte er nun aber den Widerstand der von Strauß angeführten deutschen Atomlobby, die ohnehin wenig Interesse besaß, die deutsche Atompolitik durch EURATOM kontrollieren zu lassen 230 .

Vor dem Hintergrund dieser Schwierigkeiten lud Spaak die Außenminister der

${ }^{223}$ S. Aufzeichnung Valéry, 2. 2. 1956, in: DDF 1956, Bd. 1, S. 135-140; Küsters, Gründung, S. 232 f. 224 Vgl. Bührer, Westdeutschland, S. 360f.; Weilemann, Anfänge, S. 64-66.

225 S. Furler an Hallstein, 30. 1. 1956, in: Wilkens (Hg.), Interessen verbinden, S. 401-409; Entschließung und Gemeinsame Erklärung des Aktionskomitees für die Vereinigten Staaten von Europa, in: Bulletin 1956, S. 155f.; Roussel, Jean Monnet, S. 712f.; Schröder, Jean Monnet, S. 429-431; Weilemann, Anfänge, S. 70-74.

226 Vgl. die Dokumente in: FRUS 1955-1957, Bd. 4, S. 378-417; Bossuat, Jean Monnet, S. 324-329; Eckert, Kernenergie, S. 322-325.

227 S. Regierungserklärung Mollets, 31. 1. 1956, in: JO, Ass. Nat., Déb. parl. 1956, Bd. 1, S. 135-139.

${ }_{228}$ Billotte an Faure und Pinay, 24. 1. 1956, in: DDF 1956, Bd. 1, S. 74-76, hier S. 76.

229 S. Guillen, La France et la négociation du traité d'Euratom, S. 308 f.; Wilkens, Jean Monnet, S. 125.

230 S. Conant an Dep. of State, Tel. 2715, 9. 2. 1956, Confidential, in: FRUS 1955-1957, Bd. 4, S. 413415; Eckert, Kernenergie, S. 325; Fischer, Atomenergie, S. $281 \mathrm{f}$. 
EGKS Anfang Februar zu einer Konferenz nach Brüssel ein ${ }^{231}$. Vier zentrale Probleme galt es zu bereinigen: die Tendenz zur Abkehr von der Atomgemeinschaft à six, die Frage der militärischen Nutzung der Atomenergie, die Regelung der Eigentumsrechte bei spaltbarem Material sowie die zeitliche Abfolge der Gründung von EURATOM und Gemeinsamem Markt. Gegenüber dem französischen Botschafter ließ der belgische Außenminister vorab den Wunsch durchblicken, beide Integrationsvorhaben später miteinander verbinden zu wollen, wohl wissend, daß der Gemeinsame Markt nur in mehreren Etappen zu schaffen sei. Die militärische Nutzung der Kernenergie wollte er im Falle der Gründung von EURATOM persönlich nicht ausschließen ${ }^{232}$.

In der Bundesregierung konnten sich die widerstrebenden Flügel auf keine einvernehmliche Richtschnur einigen. Nach einer Kabinettssitzung hieß es am 10. 2. gegenüber der Presse, man sähe zwischen EURATOM und dem OEEC-Projekt keinen Widerspruch und wolle daher das eine realisieren, ohne das andere zu vernachlässigen ${ }^{233}$. Einen Tag später hieß Spaak seine Kollegen willkommen. Die in der Literatur anzutreffende These einer nun aufbrechenden Interessendifferenz zwischen der Bundesrepublik und Frankreich, die sich darin manifestiert habe, daß Pineau die militärische Option für die Nuklearenergie offen gehalten, von Brentano aber nur die friedliche Nutzung reklamiert und außerdem eine gleichzeitige Verwirklichung von EURATOM und Gemeinsamen Markt verlangt habe ${ }^{234}$, läßt sich so nicht aufrechterhalten. Spaak gab zunächst einen Überblick über die bisherigen Arbeitsergebnisse seines Ausschusses zum Thema Gemeinsamer Markt. Die Delegationsleiter hatten sich inzwischen auf die Form einer Zollunion geeinigt und darauf verständigt, die erste Phase nicht als eine Versuchsetappe anzusehen, nach deren Abschluß das Gesamtwerk noch in Frage gestellt werden könne. Die Probleme der Festsetzung des Außentarifs, der Kontingente und der Marktordnungen auf dem Gebiet der Landwirtschaft waren noch offen. Nachdem Spaak den Gesamtbericht für den 15. 3. in Aussicht gestellt hatte, ergriff Pineau das Wort und kündigte eine sehr genaue Prüfung nicht zuletzt durch Wirtschaftsfachleute an. Erst danach sei Frankreich in der Lage, eine endgültige Stellungnahme abzugeben. Dem Gemeinsamen Markt, so stellte er in verklausulierter Form klar, werde man erst dann zustimmen, wenn die Bedenken der öffentlichen Meinung ausgeräumt seien. Pineau billigte gemäß dem kruden Dolmetscherchinesisch des Protokolls die Auffassung Spaaks, daß die Organe „ebenso viel Autorität besitzen müßten, wie der Vertrag elastisch sei“. Er plädierte dafür, nur solche Bestimmungen aufzunehmen, die flexibel genug seien, um den sich verändernden politischen Verhältnissen angepaßt werden zu können. Von Brentano nahm die Anregung Pineaus einer Prüfung des Abschlußberichts durch Wirtschaftsexperten auf und schlug eine Tagung der Wirtschaftsminister vor. In Übereinstimmung mit Spaak vertrat er die Auffassung, daß die Institutionen echter Zuständigkeiten und einer wirklichen Autorität um so mehr bedürften, je elastischer der Vertrag

231 Vgl. Küsters, Gründung, S. 235.

232 S. Rivière an Pineau, Tel. 49/54, 6. 2. 1956, Priorité, Réservé, in: DDF 1956, Bd. 1, S. 165-167.

${ }^{233}$ S. Kabinettssitzung, 10.2. 1956, in: Kabinettsprotokolle, Bd. 9, S. 187/191; de Margerie an dens., Tel. 474/76, 10. 2. 1956, Urgent, in: DDF 1956, Bd. 1, S. 178.

$234 \mathrm{Vgl}$. Küsters, Gründung, S. 235. 
gehalten sei. Von der Befassung der Wirtschaftsminister wollte Pineau aber nichts wissen. Ihm schwebte zunächst die Erörterung durch die nationalen Wirtschaftsverbände vor, und zwar bevor die Regierungen ihre Richtlinien für die Abfassung des Vertrags ausgearbeitet hätten. Erst dann schien ihm die Einschaltung der Wirtschaftsminister ratsam. Spaak stellte allseitige Zustimmung zu diesen Ausführungen fest und wandte sich dann seinem Exposé über den Stand der Arbeiten zu EURATOM zu. Eine völlige Entsagung bei der nicht-zivilen Nutzung der Kernenergie hielt er für politisch unklug. Notwendig schien ihm aber der Verzicht auf jede einseitige militärische Verwendung. Zur Frage der Verbindung zwischen EURATOM und Gemeinsamem Markt hielt er eine Stellungnahme der Regierungen zum gegebenen Zeitpunkt für notwendig. Wieder war es Pineau, der sich zuerst meldete. Er betonte den Wunsch nach einem raschen Abschluß des Vertrages über EURATOM, möglichst noch vor dem Sommer. Ziel der Atomgemeinschaft müßten die Entwicklung der Nuklearindustrie durch die Zusammenlegung von Kenntnissen, Rohstoffen und Spezialausrüstungen sowie der Aufbau eines Kontrollsystems sein, damit der heimliche Einsatz der Atomenergie zu militärischen Zwecken ausgeschlossen werde. Ihm schwebte ein gemeinsamer Markt des spaltbaren Materials und der Spezialausrüstungen ohne mengenmäßige Beschränkungen, Zölle oder Ausfuhrkontrollen vor. Zum heiklen Problem der Eigentumsrechte bemerkte er, daß die verarbeitende Industrie verstaatlicht oder privat sein könne. Die Frage nach der militärischen Nutzung der EURATOM wollte Pineau von der zukünftigen Entwicklung in der Abrüstungsproblematik abhängig machen. Von Brentano blieb nichts anderes übrig, als zu lavieren. Die Haltung der Bundesregierung sei noch nicht definitiv fest, meinte er kleinlaut. Über die militärische Nutzung verlor er kein Wort. Die Frage des Eigentums betrachtete er als völlig theoretisch. Die Monopolstellung der EURATOM beim Ein- und Verkauf von spaltbarem Material hielt er bei ausreichender Kontrolle für entbehrlich. Hinsichtlich der Verbindung zwischen EURATOM und Gemeinsamem Markt ließ er erkennen, daß ihm das von Frankreich bevorzugte ,Europa der zwei Geschwindigkeiten" nicht behagte. Er bevorzugte statt dessen eine gleichzeitige Vereinbarung über beide Projekte. Angesichts der von ihm sehr wohl konzedierten besonderen Schwierigkeiten in bezug auf die Entscheidung über den Gemeinsamen Markt gab er sich mit der Formel zufrieden, daß der Beschluß über EURATOM fallen dürfe, wenn eine grundsätzliche Einigung über den Gemeinsamen Markt getroffen und ein fester Wille erkennbar sei, es nicht bei einer zweiten Teilintegration zu belassen. Wenn auf dem Wege von EURATOM weiter gegangen werde, müsse die Verwirklichung des Gemeinsamen Marktes in absehbarer Zeit sichergestellt sein. Dies reichte den Vertretern Italiens und der Niederlande aber nicht aus. Martino und Beyen forderten ein klares Junktim beider Projekte. Spaak faßte die Diskussion schließlich ohne Widerspruch der Kollegen dahin zusammen, daß die Frage der militärischen Nutzung der Kernenergie nicht prinzipiell ausgeschlossen werde, das Problem Vermietung oder Verpachtung des spaltbaren Materials nicht ausschlaggebend sei und der Regierungsausschuß seine Arbeit fortsetzen könne. Hinsichtlich der Konkurrenz zwischen EURATOM und dem OEEC-Plan waren die Minister allgemein der Auffassung, eine gemeinsame Position gegenüber der OEEC formulieren und die engere Form der Zusammenarbeit bei EURATOM 
fortsetzen zu müssen. Sie kamen schließlich überein, unmittelbar nach der Abgabe des Abschlußberichtes durch Spaak erneut zusammenzukommen ${ }^{235}$.

Die tiefe Kluft zwischen den unterschiedlichen europapolitischen Zielsetzungen, wie sie die Brüsseler Außenministerkonferenz erneut manifestiert hatte, zeigte sich auch in der nun wieder aufgenommenen Arbeit des Spaak-Komitees. Die Diskussionen verliefen "plus que véhéments" und brachten kaum Fortschritte ${ }^{236}$. Am 8. 3. schickte Spaak von der Groeben und Uri mit seinem Mitarbeiter Hupperts nach Südfrankreich, damit sie abseits des Brüsseler Trubels den Abschlußbericht redigierten. Um sich den notwendigen Freiraum zu verschaffen, versicherte er kurz darauf, mit dem Rapport allenfalls Empfehlungen an die Regierungen aussprechen zu wollen ${ }^{237}$.

Die bei der Abfassung auftretenden Schwierigkeiten ließen es indes nicht zu, das Dokument wie geplant Mitte März fertigzustellen. Erst Anfang April legten von der Groeben, Uri und Hupperts einen Entwurf vor, der nach redaktionellen Überarbeitungen am 20. 4. vom Lenkungsausschuß angenommen wurde ${ }^{238}$. Einen Tag später präsentierte Spaak das Schriftstück der Presse. Man sah dem Text an, daß er lediglich den kleinsten gemeinsamen Nenner unterschiedlicher wirtschaftsund integrationspolitischer Vorstellungen darstellte: schrittweise Schaffung eines Gemeinsamen Marktes innerhalb von zwölf Jahren in der Form einer vollständigen Zollunion; Abbau der Binnenzölle in drei Etappen à vier Jahren; Festlegung des Außenzolls auf der Basis des arithmetischen Mittels der bestehenden Tarife; Abbau der mengenmäßigen Beschränkungen bei den Importen aus Mitgliedsländern im Rhythmus der Senkung der Binnenzölle; Ausdehnung der Liberalisierung auf die Landwirtschaft mit Übergangs- und Schutzmaßnahmen mittels Anpassungs- und Investitionsfonds; Schaffung einer Atombehörde mit gemeinsamer Forschungs- und Investitionspolitik und Versorgung der Industrie mit Erzen und Kernbrennstoffen ${ }^{239}$.

Nach monatelangen gedanklichen Vorbereitungen, Vorbesprechungen und Verhandlungen lag damit ein konkretes Projekt zur Fortsetzung der zwei Jahre zuvor gestoppten europäischen Einigung vor. Der Spaak-Bericht trug freilich in all seinen Teilen „Zeichen des Kompromisses“240, deren Tragfähigkeit noch keineswegs erwiesen war. Denn es schien weder der Streit zwischen Institutionalisten und Funktionalisten, Befürwortern der vertikalen und der horizontalen, der sektoralen bzw. gesamtwirtschaftlichen Integration ausgestanden noch geklärt, ob sich die Verfechter der Integration gegenüber den Anhängern der Kooperation souveräner Nationalstaaten würden durchsetzen können.

235 S. PA, Abt. 2, Bd. 904, Bl. 82-136, Konferenz der EGKS-Außenminister vom 11./12. 2. 1956, MAE 61d/56, 28. 2. 1955, Entwurf; Valéry an Pineau, Aufzeichnung, 15. 2. 1956, in: DDF 1956, Bd. 1, S. 207-210; AMAE, DE-CE, Bd. 613, Bl. 27-31, Zirkularaufzeichnung der Unterabt. für wirtschaftliche Kooperation im MAE, 17. 2. 1956; Dumoulin, Travaux, S. 207 f.; Pineau/Rimbaud, Grand Pari, S. 200 f.; Weilemann, Anfänge, S. 78-80.

236 Pineau/Rimbaud, Grand Pari, S. 202; s.a. Dumoulin, Travaux, S. 209.

237 S. Bulletin 1956, S. 515; Dumoulin, Travaux, S. 209.

238 S. von der Groeben, Deutschland, S. 276-278; Küsters, Gründung, S. 237-239; AdG 1956, S. 5764H.

${ }^{239}$ S. Spaak-Bericht, 21. 4. 1956, in: Schwarz (Hg.), Aufbau, S. 277-334; Aufzeichnung Valéry, 25. 4. 1956, in: DDF 1956, Bd. 1, S. 645-654; Küsters, Gründung, S. 239-251; Weilemann, Anfänge, S. 81-86.

240 Loth, Weg, S. 121. 